

\section{Sumário}

EDITORIAL

Ingo Wolfgang Sarlet, Lilian Rose Lemos Rocha e Patrícia Perrone Campos Mello

1. Direitos Fundamentais, hermenêutica e meio ambiente

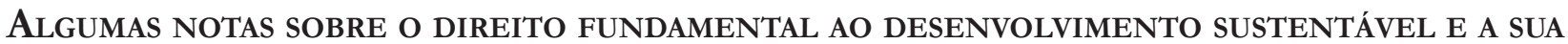
DIMENSÃO SUBJETIVA E OBJETIVA.

Ingo Wolfgang Sarlet e Gabriel de Jesus Tedesco Wedy

El DERECHO HUMANO AL AGUA Y AL SANEAMIENTO.

Belén Burgos Garrido

Até onde VAi o DiReito CONSTITUCIONAL Ao MEIO AMBIENTE ECOlOGICAMENTE EQUILIBRADO? UMA ANÁLISE SOBRE O POSICIONAMENTO BRASILEIRO FRENTE AO NOVO CONSTITUCIONALISMO

LATINO-AMERICANO

Mariana Bruck de Moraes Ponna Schiavetti e Maria Eugênia Bruck de Moraes

El DERECHO HUMANO AL ACCESO A LA INFORMACIÓN AMBIENTAL Y LA JURISPRUDENCIA INTERAMERICANA.

Gonzalo Aguilar Cavallo Garrido

As MÚlTIPLAS DIMENSÕES DO DIREITO FUNDAMENTAL À CIDADE.

Zenildo Bodnar e Priscilla Linhares Albino

Na dúvida EM Favor da natureza? LeVar a sério a Constituição Ecológica na Época do Antropoceno.

Patryck de Araújo Ayala e Mariana Carvalho Victor Coelho

2. Direitos dA NATUREZA................................................................................. 164

A sala de EMERgênCia Ambiental: A PRoteÇão dos direitos da natureza na AmÉrica

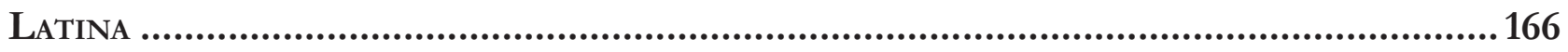

Lilian Rose Lemos Rocha

Procedural theory of THE SubJect of LAW AND NON-HUMan ANimals: CRiteria for RECOGNITION OF LEGAL SUBJECTIVITY FROM THE PERSPECTIVE OF CRITICAL THEORY

Sthéfano Bruno Santos Divino 
Os “ANIMAIS DE PRODUÇÃO” PARA ALIMENTAÇÃO HUMANA E O DIREITO CONSTITUCIONAL AMBIENTAL E ECOLÓGICO: PARADOXOS ÉTICO-JURÍDICOS

Juliane Caravieri Martins e Cicília Araújo Nunes

3. Povos indígenas

Povos Indígenas E PRoteção da NATUREZA: A CAMINHO DE UM “GIRO HERMENÊUTICo ECOCÊNTRICO"

Patrícia Perrone Campos Mello e Juan Jorge Faundes Peñafiel

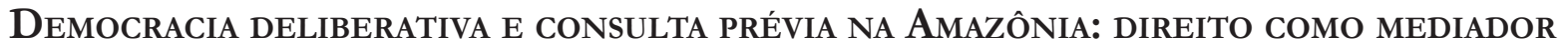

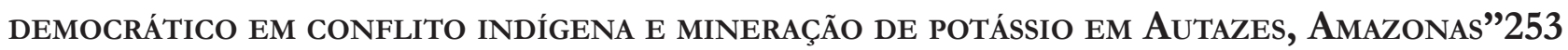
Acursio Ypiranga Benevides Júnior

Rafael da Silva Menezes

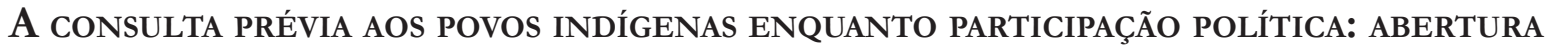
CONSTITUCIONAL BRASILEIRA A ROTAS ALTERNATIVAS DE PROTEÇÃO AMBIENTAL.

Laura Fernanda Melo Nascimento e Adriano Fernandes Ferreira

4. ECOFEMINISMO

MEIO AMbIENTE, CUIDADo E DIREITO: INTERSECÇÕES TEÓRICAS E PRÁTICAS DESDE A DIALÉTICA DA DIFERENÇA 294

Gustavo Seferian e Carol Matias Brasileiro

ECOFEMINISMO INTERSECCIONAL E DECOLONIAL NO DIREITO BRASILEIRO: A NOVA POLÍTICA estadual de SEgurança de barRagens de Minas Gerais.

Émilien Vilas Boas Reis e Vanessa Lemgruber

\section{INSTRUMENTOS E INCENTIVOS PARA A CONCRETIZAÇÃO DA PROTEÇÃO AO MEIO} AMBIENTE

STARTUP E O DESAFIO DO COMPLIANCE

Grace Ladeira Garbaccio, Alexandra Aragão, Vanessa Morato Resende e Ana Walêska Xavier Araújo

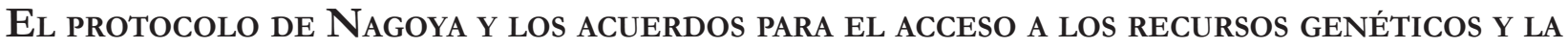
PARTICIPACIÓN JUSTA Y EQUITATIVA EN LOS BENEFICIOS QUE SE DERIVEN DE SU UTILIZACIÓN: UNA PROPUESTA DISCUTIDA

Roberto Concha Machuca

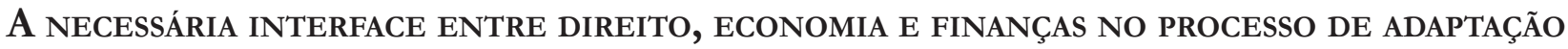
Às MUDANÇAS CLIMÁTICAS 363

Fernanda Dalla Libera Damacena 
RELEVÂNCIA E ESTRATÉGIAS PARA VIABILIZAÇÃo DA CRIAÇÃO DE CORREDORES ECOLÓGICOS EM Área da Mata Atrântica setentrional

Juliana Garcia Vidal Rodrigues, Sueli Aparecida Moreira e Eliza Maria Xavier Freire

AgrotóXICOS, DOMINAÇÃO E FRONTEIRAS: SIGNIFICAÇÃO, RELAÇÃO E PERSPECTIVAS SOBRE O PACOTE TECNOLÓGICO AGRÍCOLA E A AMAZÔNIA BRASILEIRA 418

Giovanni Martins de Araújo Mascarenhas, José Antônio Tietzmann e Silva e Luciane Martins de Araújo

SERÁ O SANEAMENTO BÁSICO UMA ESPÉCIE DE SERVIÇO PÚBLICO DE INTERESSE LOCAL? UM ESTUDO À LUZ DA TEORIA DAS CAPACIDADES ESTATAIS APLICADA AOS MUNICÍPIOS BRASILEIROS.. 440 Thaís de Bessa Gontijo de Oliveira e Fabiana de Menezes Soares

IMPASSES DA ADOÇÃO DA TÉCNICA DE DESSALINIZAÇÃO: BENEFÍCIOS PARA A SAÚDE PÚBLICA E DANOS PARA O MEIO AMBIENTE.

Ivone Rosana Fedel, André Studart Leitão e Gerardo Clésio Maia Arruda

As CONTRATAÇõES PÚBliCAS SUSTENTÁVEIS E A IMPLEMENTAÇão DA META 12.7 DOS OBJETIVOS PARA O DESENVOLVIMENTO SUSTENTÁVEL (ODS) NO BRASIL: AVANÇOS E RETROCESSOS .492 Lucas Campos Jereissati e Álisson José Maia Melo

6. Acesso À justiça em matéria AMbiental.

Desafíos del acceso a la justicia Ambiental en Chile. Jairo Enrique Lucero Pantoja, Gonzalo Aguilar Cavallo e Cristian Contreras Rojas

CONSIDERAÇÕES SOBRE A PARTICIPAÇÃO JUDICIAL DIRETA EM DEFESA DO MEIO AMBIENTE NO Brasil, No Equador e na Bolívia . .556 Leonardo Leite Nascimento e Valmir César Pozzetti

JURISDIÇÃo CONSTITUCIONAL E PATRIMÔNIO CULTURAL: UM ESTUdO DE CASO DA ADPF 206.575 Almir Megali Neto, Flávio Couto Bernardes e Pedro Augusto Costa Gontijo

A TESE DE IMPRESCRITIBILIDADE DE DANOS AMBIENTAIS EM REPERCUSSÃO GERAL DO SUPREMO TRIBUNAL FEDERAL E A POSSIBILIDADE DE APLICAÇÃO DA TEORIA DO RISCO AGRAVADO............602 Vicente de Paulo Augusto de Oliveira Júnior e Daniel Pagliuca

7. Mudanças Climáticas.

Agenda 2030: EMERgênCIA CLIMÁtiCa E O PAPEL DAS INSTITUIÇões PÚBLICAS .624 Luiz Edson Fachin

DÉfis ET PERSPECTIVES POLITIQUES, INSTITUTIONNELles ET NORMATIVES DES AsSEMbléES CITOYENNES: UNE APPROCHE DEPUIS L'EXEMPLE DE LA CONVENTION CITOYENNE SUR LE CLIMAT .636

Benoit Delooz 
Cambio Climático e Inversiones: Esbozando estrategias de armonización para

Andrea Lucas Garí, Jaime Tijmes-Ihl e Johanna Sagner-Tapia

MudANÇAS CLIMÁTICAS E RESPONSABILIDADE CIVIL: UM ESTUDO DE CASO SOBRE A REPARAÇÃo DE

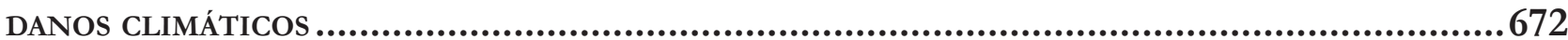

Sabrina Jiukoski da Silva e Thatiane Cristina Fontão Pires 


\title{
Povos Indígenas e proteção da natureza: a caminho de um "giro hermenêutico ecocêntrico"**
}

\section{Indigenous Peoples and nature protection: on the way to an "ecocentric hermeneutic turn"}

\author{
Patrícia Perrone Campos Mello** \\ Juan Jorge Faundes Peñafiel***
}

\section{Resumo}

O presente trabalho tem o propósito de examinar: (i) o papel que os Povos Indígenas, as normas constitucionais que os protegem e respectivas instituições podem desempenhar na defesa da Natureza, e vice-versa; (ii) um possível giro hermenêutico na interpretação de tais normas, implicando a superação de um paradigma antropocêntrico por um paradigma ecocêntrico, com potencial de ressignificação de toda a ordem jurídica. Com esse propósito, a seção 1 explica alguns conceitos e categorias operacionais; as seções 2 e 3 tratam do regime constitucional aplicável aos Povos Indígenas e à Natureza; a seção 4 trata das normas de Direito Internacional dos direitos humanos que os regulam. A seção 5 explica a relação de proteção recíproca entre Povos Indígenas e meio ambiente. A seção 6 aborda o referido giro hermenêutico constitucional. $\mathrm{O}$ trabalho se baseia essencialmente em revisão bibliográfica.

Palavras-chave: Povos Indígenas. Meio ambiente. Identidade cultural. Hermenêutica intercultural. Antropocentrismo. Ecocentrismo.

** Professora do Programa de Mestrado e Doutorado do Centro Universitário de Brasília - UniCEUB e Professora Colaboradora no Programa de Mestrado da Universidade de São Paulo - USP-Ribeirão. Doutora e mestre pela Universidade do Estado do Rio de Janeiro UERJ. Visiting Scholar no Max Planck Institute of Comparative Public Law and International Law, Heidelberg, Alemanha. Procuradora do Estado do Rio de Janeiro. Assessora de Ministro do Supremo Tribunal Federal, Brasil.

E-mail: patriciaperrone@uol.com.br

*** Professor Investigador do Instituto de Investigación en Derecho e do Dotorado em Direito, ambos da Universidad Autónoma de Chile. Doutor em Procesos Sociales y Políticos en América Latina pela Universidad de Artes y Ciencias Sociales, Chile. Advogado pela Universidad Austral de Chile. Autor do livro "Horizontes constituyentes. Reconocimiento de los pueblos indígenas en América Latina. Los casos de Chile y Bolivia" (Curitiba, Brasil, Appris, 2020) y coeditor do livro "Derecho fundamental a la identidad cultural, abordajes plurales desde América Latina" (Santiago, RIL Editores, UA, 2020). E-mail: juanjorgef@gmail.com

\section{Abstract}

The present work aims to examine: (i) the role that Indigenous Peoples, their constitutional regime and institutions can play in the protection of Nature, and vice-versa; (ii) a possible hermeneutic turn in the interpretation of the mentioned regimes, which implies the overcoming of an anthropocentric paradigm by an ecocentric paradigm, with the potential to re-signify the entire legal order. With this purpose, section 1 covers some operational concepts and categories; sections 2 and 3 deal with the constitutional regime applicable to Indigenous Peoples and Nature; section 4 deals with international human rights law on the matter; section 5 explains the relationship of reciprocal protection between Indigenous Peoples and the environment; section 6 addresses the mentioned hermeneutic turn. The work is essentially based on bibliographic review.

Keywords: Indigenous Peoples. Environment. Cultural identity. Intercultural hermeneutics. Anthropocentrism. Ecocentrism. 


\section{Introdução}

Este artigo é escrito em tempos de muita apreensão, que combinam avanços humanos notáveis em diversas áreas do saber, com intervenções sobre a Natureza que colocam em risco o equilíbrio planetário e, possivelmente, a própria sobrevivência da espécie humana ${ }^{1}$. Entre tais alterações ambientais, estão a mudança do ciclo do carbono, com alta concentração desse gás na atmosfera e aquecimento do clima; a interferência no ciclo de outros componentes relevantes para a vida na Terra, como o nitrogênio, o fósforo e o enxofre; a modificação do ciclo da água, pela interceptação e alteração do curso de rios e modificação da cobertura dos solos; a consequente extinção massiva e acelerada de espécies, a ponto de se falar que se encontra em curso a sexta grande extinção em massa de espécies experimentada na história do planeta (a quinta foi aquela em que se extinguiram os dinossauros) ${ }^{2}$.

Tais elementos são responsáveis pela crise climática atualmente experimentada, que envolve a ocorrência, cada vez mais presente, de eventos extremos (furacões, inundações e grandes secas), o derretimento das calotas polares, a elevação do nível do mar, uma grande supressão da biodiversidade; risco para o acesso à água potável, para a segurança alimentar e para a geração de energia; desertificação e savanização de grandes áreas, agravamento da situação de grupos humanos vulneráveis e possibilidade de grandes migrações em busca de melhores condições de vida. Todos esses fatores são atribuídos, predominantemente, à ação humana, notadamente no que respeita ao uso de combustíveis fósseis, à alteração no uso e cobertura do solo (relacionados à agricultura e pecuária) e ao desmatamento, entre outros fatores ${ }^{3}$. Trata-se de uma crise que coloca em xeque nosso modo de produzir, de viver e, acima de tudo, de compreender e nos relacionar com a Natureza e que sugere a necessidade de uma profunda alteração de paradigmas.

O Brasil é parte do problema e da solução para a crise climática. Abriga importantes áreas de floresta, entre as quais a Floresta Amazônica, que ocupa 49\% do território do país ${ }^{4}$, é responsável pela absorção e armazenamento de dióxido de carbono da atmosfera (contribuindo para o resfriamento do planeta) e promove a transferência de grandes volumes de água para o continente sul-americano. A Amazônia constitui, ainda, a maior reserva de biodiversidade da Terra e tem influência decisiva na estabilidade climática do Brasil e do planeta ${ }^{5}$. Em tal contexto e em resposta a pressões internacionais, o país começou a reverter, a partir de 2004, uma tendência persistente ao desmatamento e contribuiu de forma muito substancial para a redução da emissão de gases de efeito estufa ${ }^{6}$. Entretanto, a partir de 2013, retomou uma tendência crescente à

\footnotetext{
1 Alguns cientistas consideram a possibilidade de que a magnitude do poder exercido pela espécie humana sobre a Natureza, bem como dos efeitos que ele produz, permitiria falar em uma nova era geológica do planeta, denominada Antropoceno (que sucederia o Holoceno, período quaternário da era Cenozoica). O Antropoceno teria por característica justamente a prevalência do poder do homem sobre a Natureza, no que respeita à determinação dos processos ecológicos. Embora o termo Antropoceno tenha ganhado popularidade e seja muito utilizado, ele, ainda, não conta com uma adesão científica formal. A hipótese de uma nova era geológica é objeto de estudos voltados a confirmá-la. STEFFEN, Will et al. The Anthropocene: conceptual and historical perspectives. Philosophical Transactions of the Royal Society, n. 369, p. 842-867, 2011.

2 CEBALLOS, Gerardo et al. Accelerated modern human-induced species losses: Entering the sixth mass extinction. Science Advances, p. 1-5, 2015.

3 BARROSO, Luís Roberto; MELLO, Patrícia Perrone Campos. Como salvar a Amazônia: por que a floresta de pé vale mais do que derrubada. Revista de Direito da Cidade, v. 12, n. 2, p. 331-376, 2010.

4 De acordo com o Instituto: "A Amazônia Legal é uma área que corresponde a 59\% do território brasileiro e engloba a totalidade de oito estados (Acre, Amapá, Amazonas, Mato Grosso, Pará, Rondônia, Roraima e Tocantins) e parte do Estado do Maranhão. [...]. O conceito de Amazônia Legal foi instituído em 1953 e seus limites territoriais decorrem da necessidade de planejar o desenvolvimento econômico da região e, por isso, não se resumem ao ecossistema de selva úmida, que ocupa 49\% do território nacional e se estende também pelo território de oito países vizinhos". INSTITUTO DE PESQUISA ECONÔMICA APLICADA. O que é? Amazônia Legal. Disponível em: https://www.ipea.gov.br/desafios/index.php?option=com_content\&id=2154:catid=28\& Itemid. Acesso em: 29 set. 2020.

5 ABRAMOVAY, Ricardo. Amazônia: por uma economia de conhecimento da natureza. São Paulo: Elefante, 2019.

- CAPOBIANCO, João Paulo Ribeiro. Governança socioambiental na Amazônia brasileira na década de 2000. 2017. Tese (Doutorado) Instituto de Energia e Ambiente, Universidade de São Paulo, São Paulo, 2017; VERÍSSIMO, Beto. Let’s cut Amazon deforestation to zero. Here's how. Americas Quarterly, nov. 2015; KALUNGA, Bernardo. Desmatamento na Amazônia é ideológico, diz economista
} 
supressão de florestas, situação substancialmente agravada, em $2019^{7}$, pela assunção de um governo que não tem por prioridade a questão ambiental ${ }^{8}$.

A tal quadro preocupante, agrega-se a informação de que a Floresta Amazônica tem um "ponto de não retorno", que gravita entre $20 \%$ e $40 \%$ de desmatamento. Uma vez alcançado tal ponto, ela passará por mudanças irreversíveis, com tendência à savanização e comprometimento de todos os serviços ambientais que presta para a manutenção do clima ${ }^{9}$. Esse é o contexto em que se insere o presente trabalho.

O Brasil abriga, ainda, aproximadamente, 896.917 indígenas, 305 etnias e 274 línguas nativas ${ }^{10}$. Estima-se que vivem no país 114 povos indígenas isolados ${ }^{11}$, correspondentes a maior quantidade de povos em isolamento no mundo em um mesmo Estado ${ }^{12}$. Os Povos indígenas receberam substancial proteção da Constituição de 1988, que lhes assegurou as terras que ocupam (incluídas todas aquelas necessárias à preservação de seu modo de vida), bem como o seu usufruto perpétuo. Trata-se de povos detentores de valiosos conhecimentos sobre a floresta, que, de modo geral, estabeleceram, com a Natureza, relação muito distinta da sociedade dominante. Trata-se, igualmente, de povos extremamente vulneráveis, permanentemente ameaçados por fatores muito semelhantes àqueles que colocam o próprio meio ambiente em risco e extremamente interdependentes da Natureza para a sua subsistência ${ }^{13}$.

Diante de tal quadro, o presente trabalho se propõe a examinar: (i) a contribuição que os Povos Indígenas podem oferecer para a proteção da Natureza; (ii) a contribuição que a Natureza pode oferecer para a proteção de tais Povos; (iii) um possível "giro hermenêutico" (alteração de paradigmas), em matéria de interpretação constitucional, decorrente da interação entre crise climática, hermenêutica intercultural e hermenêutica ambiental. Trata-se de debate extremamente relevante, já que se relaciona com o enfrentamento da crise ambiental antes aludida.

Com esse propósito, a seção 1 abordará, brevemente, algumas categorias e conceitos operacionais. A seção 2 examinará o regime jurídico aplicável aos povos indígenas à luz da Constituição de 1988. A seção 3 terá

Ricardo Abramovay. Uol, 2020. Disponível em: https://tab.uol.com.br/noticias/redacao/2020/01/02/desmatamento-na-amazonia-e-ideologicodiz-economista-ricardo-abramovay.htm Acesso em: 9 fev. 2020.

DESMATAMENTO na Amazônia aumenta 85,3\% em 2019, aponta INPE. Veja, 14 jan. 2020. Disponível em: https://veja. abril.com.br/brasil/desmatamento-na-amazonia-aumenta-853-em-2019-aponta-inpe/ Acesso em: 26 set. 2020; Instituto Socioambiental. Novo arco do desmatamento: fronteira avança em 2019 na Amazônia. 2019. Disponível em: https://www.socioambiental.org/ pt-br/noticias-socioambientais/novoarco-do-desmatamento-fronteira-de-destruicao-avanca-em-2019-na-amazonia Acesso em: 3 mar. 2020; Instituto Socioambiental. Invasores produzem maior desmatamento em Terras Indigenas em 11 anos. 2019. Disponível em: https://www.socioambiental.org/pt-br/noticiassocioambientais/invasores-produzem-maior-desmatamento-em-terras-indigenasem-11-anos Acesso em: 10 maio 2020.

8 BARroso, Luís Roberto; MELLO, Patrícia Perrone Campos. Como salvar a Amazônia: por que a floresta de pé vale mais do que derrubada. Revista de Direito da Cidade, v. 12, n. 2, p. 331-376, 2010. p. 348-350.

9 NOBRE, Carlos et al. Land-use and climate change risks in the Amazon and the need of a novel sustainable development paradigm. PNAS, v. 113, n. 39, p. 10759-10768, 2016; LOVEJOY, Thomas E.; NOBRE, Carlos. Amazon Tipping Point. Science Advances, 2018. Disponível em: http://advances.sciencemag.org/content/4/2/eaat2340 Acesso em: 10 maio 2020.

10 O documento ressalva, contudo, que: "no que diz respeito aos números totais de língua e etnia, há ainda a necessidade de estudos linguísticos e antropológicos mais aprofundados, pois algumas línguas declaradas podem ser variações de uma mesma língua, assim como algumas etnias também se constituem em subgrupos ou segmentos de uma mesma etnia". INSTITUTO BRASILEIRO DE GEOGRAFIA E ESTATÍSTICA. O Brasil Indígena. Os indígenas no Censo Demográfico de 2010. Disponível em: https:// indigenas.ibge.gov.br/images/pdf/indigenas/folder_indigenas_web.pdf. Acesso em: 29 set. 2020.

11 Entre tais povos, apenas 28 estão confirmados pela Fundação Nacional do Índio - FUNAI. A confirmação dos demais depende de pesquisas ainda pendentes. INSTITUTO BRASILEIRO DE GEOGRAFIA E ESTATÍSTICA. O Brasil Indígena. Os indígenas no Censo Demográfico de 2010. Disponível em: https://indigenas.ibge.gov.br/images/pdf/indigenas/folder_indigenas_web.pdf. Acesso em: 29 set. 2020.

12 OBSERVATÓRIO DOS DIREITOS HUMANOS DOS POVOS INDÍGENAS ISOLADOS E DE RECENTE CONTATO. Povos Indígenas Isolados no Brasil: Resistência Política pela autodeterminação. 2010. Disponível em: https://povosisolados.files.wordpress.com/2020/02/informe-opi-n01v4.pdf. Acesso em: 30 set. 2020.

13 É certo que todos os seres vivos necessitam de um meio ambiente saudável para sobreviver. Entretanto, alguns grupos dependem de forma mais imediata de tal bem, bem como dos elementos que o constituem. No caso dos Povos Indígenas, a poluição de um rio ou a alteração de um microclima pode ser suficiente para inviabilizar a sobrevivência da uma comunidade, dada a relação de dependência material e cultural desenvolvida com tais elementos. 
por objeto o regime jurídico constitucional aplicável à tutela da Natureza. A seção 4 examinará a proteção dispensada a ambos, pelo Direito Internacional dos direitos humanos. A seção 5 mostrará em que medida os Povos Indígenas, a Natureza e seus respectivos regimes jurídicos se prestam a uma tutela recíproca. A seção 6 apontará uma possível alteração de paradigma na hermenêutica constitucional. Ao final, indicaremos as oportunidades que a presente crise nos gera.

Do ponto de vista metodológico, o trabalho baseia-se, essencialmente, em revisão bibliográfica ${ }^{14}$.

\section{Alguns conceitos e categorias essenciais}

A vulnerabilidade é uma condição presente em todos os seres vivos. Somos todos frágeis, finitos, destrutíveis e deixaremos de existir um dia. Há, contudo, seres, indivíduos ou grupos que são especialmente vulneráveis e mais intensamente frágeis que os demais. Essa maior vulnerabilidade relaciona-se a uma menor capacidade de resistência ou a uma menor capacidade de recuperação ou de enfrentamento ao estresse ${ }^{15}$.

Quando aplicado o conceito a humanos, alude-se, de modo geral, a grupos que não correspondem ao padrão étnico, racial, cultural, sexual, religioso, social ou econômico dominante em uma sociedade e que são especialmente estigmatizados. Em virtude de tal estigmatização, detêm um status (real) inferior aos demais cidadãos no que respeita ao exercício de seus direitos. São alvo de práticas discriminatórias. Têm dificuldade de acesso e de acolhimento de seus pleitos junto à política majoritária, onde geralmente são sub-representados ${ }^{16}$. Em razão disso, demandam técnicas específicas de proteção, que assegurem a sua defesa e promovam sua igualdade material.

Os Povos Indígenas são, nesse sentido, um grupo substancialmente vulnerável. São minoritários e divergentes do padrão dominante do ponto de vista étnico, cultural, religioso, social e econômico (ainda que em diferentes graus). Sujeitam-se a uma estigmatização histórica, que remonta à colonização portuguesa, que se estende até os dias de hoje e que foi responsável por seu quase extermínio. Têm um status real inferior aos demais cidadãos brasileiros no que respeita a um universo amplíssimo de direitos e são alvo de práticas discriminatórias, que os compreendem como primitivos, atrasados e obstaculizadores do desenvolvimento. São, ainda, sub-representados na política majoritária: no Congresso Nacional, há, apenas, uma deputada federal indígena ${ }^{17}$ e o atual chefe do Executivo já se posicionou contra a demarcação das suas terras ${ }^{18}$. Con-

\footnotetext{
14 Uma ressalva nos parece importante: por uma opção dos autores, o trabalho não desenvolve um estudo da jurisprudência brasileira a respeito da temática. Entendemos que os aportes teóricos apresentados neste artigo são suficientes alcançar suas finalidades e refletem o estado da arte da discussão no Brasil. Por outro lado, a inclusão da abordagem jurisprudencial tornaria o artigo excessivamente extenso e esbarraria em limites de espaço. De todo modo, para análise da jurisprudência sobre a proteção dos direitos dos Povos Indígenas em conexão com a proteção ao território, à identidade cultural e ao meio ambiente. MELLO, Patrícia Perrone Campos; FAUNDES, Juan Jorge. Constitucionalismo em rede: o direito à identidade cultural dos povos indígenas como filtro hermenêutico para tutela da tradicionalidade da ocupação da terra. In: ROSSITO, F. D. et al. Quilombolas e outros povos tradicionais. Curitiba: CEPEDIS, 2020. p. 317-339; para exame da jurisprudência dos tribunais superiores sobre a proteção da Natureza, bem como da adoção de argumentos antropocêntricos, bio ou ecocêntricos, SARLET, Ingo Wolfgang; FENSTERSEIFER, Tiago. Direito constitucional ecológico. 6. ed. São Paulo: Revista dos Tribunais, 2019.

15 BRANDÃO, Juliana Mendanha; MAHFOUD, Miguel; GIANORDOLI-NASCIMENTO, Ingrid Faria. A construção do conceito de resiliência em psicologia: discutindo as origens. Paidéia, v. 21, n. 49, 2011.

16 MELLO, Patricia Perrone Campos. Proteção à vulnerabilidade na jurisprudência do Supremo Tribunal Federal do Brasil: a defesa da população LGBTI+. Revista da AGU, Brasília, v. 19, n. 1, p. 17-43, jan./mar. 2020; BELTRÃO, Jane Felipe et al. Derechos humanos de los grupos vulnerables: guía de prácticas. Barcelona: DHES, Red de Derechos Humanos y Educación Superior, 2014; MARIÑO, Fernando. Introducción: aproximación a la noción de persona y grupo vulnerable en el derecho europeo. In: MARINO MENÉNDEZ, Fernando; FERNÁNDEZ LIESA, C. (org.). La protección de las personas y grupos vulnerables em el derecho europeo. Madrid: Universidad Carlos III de Madrid, 2001.

17 Segundo a matéria: Há 31 anos, desde que o cacique xavante Mário Juruna deixou o Congresso Nacional, em 1987, um índio não era eleito deputado federal. PRIMEIRA mulher indígena é eleita para a Câmara dos Deputados. Exame, out. 2018. Disponível em: https://exame.com/brasil/primeira-mulher-indigena-e-eleita-para-a-camara-dos-deputados/. Acesso em: 29 set. 2020.

18 Veja-se as manifestações atribuídas pela imprensa ao Presidente da República: "Não entro nessa balela de defender terra pra
} 
dições adversas - como aquelas que impactem sobre seu habitat — podem comprometer sua cultura e colocar a sua própria existência em risco. Demandam, portanto, técnicas especiais de proteção, entre as quais: normas substantivas que assegurem sua tutela, normas procedimentais que lhes garantam participação nas decisões que impactem sobre seus direitos, bem como instituições voltadas à proteção e promoção de tais direitos.

A Natureza também pode ser considerada, em seu conjunto ou em seus diversos componentes, como ente ("grupo") especialmente vulnerável. O sistema de proteção de direitos fundamentais que se consolidou no mundo é um sistema antropocêntrico, que tem por eixo essencial a importância e o valor da vida humana, justificados, sobretudo, com base na sua capacidade de racionalidade ${ }^{19}$. Por essa razão, a dignidade humana é reconhecida como direito-matriz, a partir do qual derivam os demais direitos fundamentais ${ }^{20}$. Em razão desse paradigma e como se verá adiante, o meio ambiente ou os diferentes bens ambientais foram, por muito tempo, compreendidos como coisas, não destinatárias da mesma proteção ou merecedoras de proteção na medida em que constituam instrumento de promoção e proteção da dignidade humana ${ }^{21}$.

A situação é particularmente grave em países marcados por economias extrativistas, exportadoras de matéria-prima e de produtos de baixo valor agregado ${ }^{22}$, como é, de modo geral, o caso das economias latino-americanas. Em tais países, os elementos da Natureza são compreendidos como recursos quase infinitos, puramente destinados à produção de riqueza e à busca por crescimento econômico ${ }^{23}$. Paradoxalmente, o modelo é defendido, com base na necessidade de superação da pobreza e de custeio de direitos sociais, bem como no argumento, puramente retórico, de se estar buscando o "desenvolvimento sustentável" do país ${ }^{24}$. Trata-se, contudo, de um sistema que conduz à exaustão dos bens naturais, à dependência econômica e ao comprometimento do meio ambiente, com graves impactos sociais. ${ }^{25}-$

índio"; "[reservas indígenas] sufocam o agronegócio" (Campo Grande News, 22.04.2015); "Em 2019 vamos desmarcar [a reserva indígena] Raposa Serra do Sol. Vamos dar fuzil e armas a todos os fazendeiros" (No Congresso, 21.01.2016); "Se eu assumir [a Presidência do Brasil] não terá mais um centímetro quadrado para terra indígena” (Dourados, Mato Grosso do Sul, 08.02.2018); "Reservas indígenas inviabilizam a Amazônia" (Revista Exame, 13.02.2020). V. Supremo Tribunal Federal. ADPF 709, rel. Min. Luís Roberto Barroso, decisão monocrática de 08.07.2020, que compilou tais manifestações.

19 KANT, Immanuel. Groundwork of the Metaphysics of Morals. Cambridge: Cambridge University Press, 1997. p. 42-47.

20 BARROSO, Luís Roberto. La dignidad de la persona bumana en el derecho constitucional contemporáneo. Bogotá: Universidad Externado de Colombia, 2014. p. 128-129.

21 SARLET, Ingo Wolfgang; FENSTERSEIFER, Tiago. Direito constitucional ecológico. 6. ed. São Paulo: Revista dos Tribunais, 2019.

22 Aguilar define o extrativismo como "a extração intensa de grandes volumes de recursos naturais principalmente para exportação (com pouco ou nenhum valor agregado) que, em geral, produz importantes impactos sociais e ambientais nos territórios”. Aguilar Castro, Vladimir. Extractivismo, derechos humanos y desafección política en Venezuela. In: SORIANO DIAZ, Ramón Luis; SANCHES RUBIO, David; Suárez Villegas, Juan Carlos (eds.). Las fronteras de los derechos bumanos: problemas, discusión y Soluciones. Madrid: Dikinson, 2020. p. 12-13.

23 Altvater et al. Las limitaciones de la globalización. economía, ecología y politica de la globalización. Madrid: Siglo XXI Ediciones, pp. 307, 327; Altvater, Elmar. ¿Existe un marxismo ecológico? In: Borón, A.; Amadeo, J. González, S. (ed.). La teoría marxista hoy, problemas y perspectivas. Buenos Aires: CLACSO, 2006. p. 341-363. p. 357; SEOANE, José; TADEI, Emilio; ALGRANATI, Clara. Movimientos sociales y bienes comunes de la naturalęa: características, significación y proyección de la conflictividad sociopolítica en América Latina. Buenos Aires, 2011. p. 4. Disponível em: https://cdsa.aacademica.org/000-034/662.pdf Acesso em: 30 set. 2020.; SEOANE, José; TADEI, Emilio; ALGRANATI, Clara. Recolonización, bienes comunes de la naturaleza y alternativas desde los pueblos. Buenos Aires: GEAL, 2010. p 9-10; HARVEY, David. El nuevo imperialismo. Madrid: AKAL, 2004.

24 A ideia de "desenvolvimento sustentável", quando é puramente retórica e não vem acompanhada de uma mudança na relação com a Natureza, pode marcarar o comportamento puramente extrativista e suas consequências. Nessa linha, a título ilustrativo, os arts. 33 e 34 da Constituição Plurinacional da Bolívia asseguram o direito ao meio ambiente e a ação popular para protegê-lo. Entretanto, entram em conflito com o art. 351 do mesmo documento e com a forma pela qual tem sido implementado. Esse último dispositivo tratou da industrialização e da comercialização dos recursos naturais que estão sob o controle do Estado; e tais atividades, na prática, são promovidas sem o desenvolvimento de um novo modelo de interação com a Natureza. V. FAUNDES, Juan Jorge P. Horizontes constituyentes. Reconocimiento de los pueblos indígenas en América Latina. Los casos de Chile y Bolivia. Curitiba: Appris, 2020, pp. 231-232; RAMIREZ, Silvina. Derechos de los pueblos indígenas y derechos de la naturaleza: encuentros y desencuentros. Derechos de los pueblos indígenas y derechos de la Naturaleza: encuentros y desencuentros. Revista Argentina de Teoría Jurídica, v. 12, dez. 2011, pp. 26-41, p. 31.

25 Aguilar Castro, Vladimir. Extractivismo, derechos humanos y desafección política en Venezuela. In: SORIANO DIAZ, Ramón Luis; SANCHES RUBIO, David; Suárez Villegas, Juan Carlos (eds.). Las fronteras de los derechos humanos: problemas, discusión y Soluciones. Madrid: Dikinson, 2020. p. 12-13; Alayza, A.; Gudynas, E. Transiciones y alternativas al extractivismo en la región andina. Lima: Centro Peruano de Estudios Sociales, 2012. p. 6-12; Acosta, A. Extractivismo y neoextractivismo: dos caras de la misma maldición. 
Além disso, e do mesmo modo que certos grupos humanos vulneráveis, a Natureza não tem "voz" própria, o que também favorece sua maior vulnerabilidade. Ela não se expressa em instâncias majoritárias. E depende da mediação de atores e de instituições que atuem na sua defesa (muito embora a magnitude das alterações climáticas e das suas consequências possa ser considerada uma importante forma de "resposta" às múltiplas violações). Há na Natureza ecossistemas mais e menos resilientes. Mas o ataque persistente a eles mina, progressivamente, sua capacidade de resistência até um "ponto de não retorno", a partir do qual ele perde suas propriedades essenciais de forma irreversível. Assim, também a Natureza demanda técnicas especiais de proteção, entre as quais: normas substantivas que assegurem sua tutela; normas procedimentais quanto à aprovação de medidas ou projetos com impacto ambiental; bem como instituições voltadas à sua proteção.

Além da vulnerabilidade, os Povos Indígenas e a Natureza têm em comum uma posição de risco diante de discursos desenvolvimentistas, já que seus propagadores compreendem as normas que os protegem como um obstáculo a ser combatido e que há uma tendência, em tempos de dificuldade, à opção por soluções imediatistas.

\section{Normas constitucionais protetivas dos Povos Indígenas}

\subsection{Direito Constitucional positivo}

A Constituição de 1988 contemplou um rol amplo de normas de proteção aos Povos Indígenas, tanto na perspectiva substantiva, quanto procedimental e institucional. Na perspectiva substantiva, assegurou aos índios "sua organização social, costumes, línguas, crenças e tradições, e os direitos originários sobre as terras que tradicionalmente ocupam" (art. 231, caput, CF). Determinou que seu direito à terra alcança aquelas "utilizadas para suas atividades produtivas, as imprescindíveis à preservação dos recursos ambientais necessários a seu bem-estar e as necessárias à sua reprodução física e cultural, segundo seus usos, costumes e tradições" (art. 231, $\$ 1^{\circ}, \mathrm{CF}$ ). A Constituição protegeu, ainda, como patrimônio cultural brasileiro, as formas de expressão e os modos de criar, fazer e viver dos Povos Indígenas (arts. 215 e 216, I e II, CF).

Em relação à perspectiva procedimental, a Carta determinou que o aproveitamento dos recursos hídricos, incluídos os potenciais energéticos, a pesquisa e a lavra das riquezas minerais em terras indígenas somente pode ser efetivado com autorização do Congresso Nacional, ouvidas as comunidades afetadas (art. 231, CF). E assegurou aos índios, suas comunidades e organizações legitimidade para ingressar em juízo na defesa de seus interesses (art. 232, CF). O direito de participação direta de indígenas e comunidades é fundamental para que possam aportar aos processos decisórios que impactam sobre suas próprias vidas perspectivas e informações que podem ser de extrema relevância para a decisão. Esse direito de participação é reforçado, ainda, por normas da Convenção 169 da OIT, que, na condição de tratado sobre direitos humanos, tem status supralegal no ordenamento brasileiro, e funciona, portanto, como standard hermenêutico e como paradigma de validade das normas infraconstitucionais, por meio do controle de convencionalidade (art. $5^{\circ}$, $\left.\$ 2^{\circ}, \mathrm{CF}\right)^{26}$.

In: LANG, M.; MOKRANI, D. Más allá del desarrollo. Quito: Fundación Rosa Luxemburgo/Abya Yala, 2012. p. 83-118; RAMÍREZ, Silvina. Derechos de los pueblos indígenas y derechos de la Naturaleza: encuentros y desencuentros. Revista Argentina de Teoría Jurídica, v. 12, p. 26-41, dez. 2011.

26 Sobre a articulação entre direito constitucional, direito internacional dos direitos humanos e direito constitucional comparado, bem como sobre o status dos tratados de direitos humanos no Brasil, v. MELLO, Patrícia Perrone Campos. Constitucionalismo, transformação e resiliência democrática no Brasil: o Ius Constitutionale Commune na América Latina tem uma contribuição a oferecer? Revista Brasileira de Politicas Públicas, v. 9, n. 2, ago. 2019, pp. 252-283. BOGDANDY, Armin von. Ius Constitucionale Commune na América Latina: uma reflexão sobre um Constitucionalismo Transformador. Revista de Direito Administrativo, Rio de janeiro, v. 269, maio/ago. 2015; ANTONIAZZI, Mariela Morales. O estado aberto: objetivo do Ius Constitucionale Commune em Direitos Humanos. In: BOGDANDY, Armin von; ANTONIAZZI, Mariela MORALES; PIOVESAN, Flávia (coord.). Ius Constitucionale 
Por fim, quanto à perspectiva institucional, a Constituição de 1988 cuidou de prever instituições voltadas à proteção dos direitos de tais Povos. Nesse sentido, atribuiu ao Ministério Público e à Defensoria Pública a defesa dos seus interesses (art. 129, V, c/c art. 232; art. 134, CF). Manteve a propriedade das terras indígenas sob o domínio da União, garantindo-lhes o usufruto perpétuo, de modo que eventuais ataques a seus territórios devem ser defendidos também pela União e por suas instituições (art. 231, CF). Previu, ainda, as ações diretas integrantes do controle concentrado da constitucionalidade, a ação civil pública e a ação popular como instrumentos de proteção a direitos fundamentais e/ou ao patrimônio histórico e cultural, que, portanto, podem utilizados na defesa de tais Povos (art. 5, LXXIII; art. 102, "a" e $\$ 1^{\circ}$ : art. 129, III).

Tal institucionalidade é complementada, em sede infraconstitucional, pela Fundação Nacional do Índio - FUNAI ${ }^{27}$, pelas Bases (BAPEs) e Frentes de Proteção Etnoambiental (FPEs) ${ }^{28}$ e pelo Subsistema Especial de Saúde Indígena ${ }^{29}$, entre outros. Essas instituições destinam-se à proteção e promoção dos direitos indígenas e têm servidores trabalhando junto às suas comunidades, muito embora venham sofrendo com uma precarização progressiva, que inclui perda e não reposição de servidores e reduções orçamentárias ${ }^{30}$.

\subsection{Hermenêutica Intercultural}

A interpretação das normas de proteção aos Povos Indígenas atrai a incidência do que se tem chamado "hermenêutica intercultural", em alusão à experiência de julgar entre duas culturas: a cultura dominante, a que geralmente pertence o juiz, e a cultura indígena. A hermenêutica intercultural chama a atenção para a perspectiva de que a experiência do juiz — como ser humano e como julgador — não é universal: está imersa em e referenciada a uma determinada cultura, que é diversa daquela em que se inserem os Povos Indígenas. Por essa razão, tal julgador, ao apreciar as causas que lhe são submetidas, deve deslocar-se do sen lugar para o lugar "do outro" e buscar compreender os conflitos de interesses que lhes são submetidos com base na perspectiva desse outro.

O princípio central que rege tal hermenêutica corresponde ao direito à identidade cultural dos Povos Indígenas. Ele expressa o direito das comunidades tradicionais e de seus membros a viverem de acordo com a sua cultura e a serem reconhecidos como diferentes nas relações com outros grupos. Abrange o interesse em conservar tal cultura, espiritualidade e referentes cosmogônicos, seu patrimônio cultural tangível e intangível, sua memória histórica e sua identidade presente. Assegura, portanto, o respeito a seus conhecimentos, línguas, crenças, artes, moral, religião, formas de justiça e de organização $0^{31}$.

O direito à identidade cultural dos Povos Indígenas, além de seu caráter substantivo, tem uma expressão objetiva e funciona como uma espécie de filtro hermenêutico, determinando que cada direito atribuído a grupos culturais minoritários e a seus membros, assim como o comportamento desses grupos e membros, devem

Commune na América Latina: marco conceptual. Curitiba: Juruá, 2016. v. 11.

27 Criada pela Lei n. 5.371/1967, com o propósito de promover e proteger os direitos dos Povos Indígenas.

28 Como esclarece Amorim: "As FPE são unidades descentralizadas da FUNAI que atuam em campo na implementação da política indigenista direcionada aos povos indígenas isolados e de recente contato. As Frentes atuam por meio das Bases de Proteção Etnoambiental, estruturas físicas localizadas no interior das terras indígenas, com o objetivo de realizar o controle de ingresso, a vigilância permanente, ações de fiscalização em conjunto com outros órgãos, realizar ações de localização e monitoramento de povos isolados, diálogo com o entorno indígena e não indígena, e ações de promoção dos direitos dos povos recém contatados”. AMORIM, Fabrício. Povos indígenas isolados no Brasil e a política indigenista desenvolvida para efetivação de seus direitos: avanços, caminhos e ameaças. Revista Brasileira de Linguística Antropológica, v. 8, n. 2, p. 19-39, 2016.

29 Criado pela Lei n9.836/1999, o Subsistema de Atenção à Saúde Indígena é descentralizado e prevê organismos colegiados de formulação, acompanhamento e avaliação das políticas de saúde, tais como o Conselho Nacional de Saúde e os Conselhos Estaduais e Municipais de Saúde. Determina, ainda, a organização do sistema em Distritos Especiais Sanitários Indígenas.

30 CONSELHO INDIGIENISTA MISSIONÁRIO. Com apenas 0,02\% do orcamento da União, valor gasto pela Funai até junho é o mais baixo em dez anos. CIMI, 2020. Disponível em: https://cimi.org.br/2020/06/com-apenas-002-orcamento-uniao-valor-gasto-funaijunho-mais-baixo-dez-anos/ Acesso em: 30 set. 2020.

31 FAUNDES, Juan Jorge. El derecho fundamental a la identidad cultural de los pueblos indígenas, configuración conforme el derecho internacional y perspectivas de su recepción en Chile. Ius et Praxis, v. 26, n. 1, p. 77-100, 2020. p. 81-82. 
ser examinados e compreendidos à luz de sua visão de mundo e dos significados que a sua comunidade dá a tais comportamentos; e não apenas à luz dos significados, das representações e da cosmovisão da cultura dominante, em que de modo geral se insere o julgador" ${ }^{32}$.

Nesse sentido e para o que interessa a este trabalho, a Natureza e diversos de seus elementos integram referentes cosmogônicos e espirituais essenciais para os Povos Indígenas. Os recursos naturais são essenciais para a preservação de seus modos de fazer, criar e viver, bem como para sua organização social, costumes, crenças e tradições e, ainda, para sua reprodução física e cultural. Há, portanto, uma relação intrínseca entre a proteção à identidade cultural dos Povos Indígenas e a proteção à Natureza ${ }^{33}$. Confira-se, sobre o ponto, discurso proferido por uma relevante líder indígena perante a Assembleia Constituinte do Equador:

[...] Segundo a cosmovisão indígena, todos os seres da natureza estão investidos da energia que é o 'samai' e, em consequência, são seres que têm vida: uma pedra, um rio (água), a montanha, o sol, as plantas, enfim, todos os seres têm vida e também disfrutam de uma família, de alegrias e tristezas, como o ser humano. [...]. Em outras palavras, podemos dizer que todos somos parte de um todo; que apesar de sermos distintos, somos complementares, nos necessitamos mutuamente. ${ }^{34}$

Tais considerações merecem, todavia, algumas ressalvas. Em primeiro lugar, os Povos Indígenas não são homogêneos. Detêm, eles próprios, distintas culturas e aspirações. Por essa razão, a proteção à Natureza que, de modo geral, é convergente com a sua cultura, pode entrar em conflito com seu direito à autodeterminação e com sua opção por desenvolver atividades potencialmente danosas ao meio ambiente. Embora o assunto não seja objeto do trabalho, a ressalva é importante, para que não se argumente de forma idealizada. Povos Indígenas também podem experimentar dinâmicas de recuperação e fortalecimento de sua cultura, ou, ao contrário, processos de perda cultural ${ }^{35}$.

Além disso, o modo de produção extrativista também exerce pressão sobre os Povos Indígenas, inclusive por meio normas voltadas a proteger seus direitos. Basta lembrar que normas internacionais (tais como os artigos 15 e 16 do Convênio 169 da OIT) e constitucionais (art. 231, $\ 3^{\circ}$, CF) reconhecem a possibilidade de que tais Povos anuam com a exploração de atividades potencialmente danosas em suas terras e lhes asseguram participação nos resultados, podendo, portanto, funcionar como um incentivo para que adiram a uma lógica de coisificação da Natureza ${ }^{36}{ }^{37}$.

\footnotetext{
32 CAVALlAZZI, Vanessa Wendhausen; MELLO, Patrícia Perrone Campos; SOARES, Raony. Educação superior intercultural, reconhecimento e redistribuição: o duro caminho dos povos indígenas no Equador. Brazilian Journal of International Law, v. 15, n. 1, p.179-198, 2018. p. 187.

33 Sobre a relação entre direito à identidade cultural e direitos territoriais indígenas, PACARI, Nina. Naturaleza y territorio desde la mirada de los pueblos indígenas. In: ACOSTA, Alberto; MARTÍNEZ YÁNEZ, Esperanza. Derechos de la Naturaleza. Quito: AbyaYala, 2009. p. 31-37; MARTÍNEZ YÁNEZ, Esperanza; ACOSTA, Alberto. La Naturaleza entre la cultura, la biología y el derecho. Polis, Revista Latinoamericana, v. 13, n. 38, p. 623-627, 2014; RAMÍREZ, Silvina. Derechos de los pueblos indígenas y derechos de la Naturaleza: encuentros y desencuentros. Revista Argentina de Teoría Jurídica, v. 12, p. 26-41, dez. 2011; SOUZA, Pablo Ronaldo Gadea de. A terra como elemento nevrálgico da identidade indígena: a violação dos direitos coletivos territoriais dos povos indígenas e seu tratamento no âmbito do sistema interamericano de proteção aos direitos humanos. Dissertação (Mestrado em Direito Constitucional) - Universidade Federal Fluminense, Rio de Janeiro, 2018.

34 PACARI, Nina. Naturaleza y territorio desde la mirada de los pueblos indígenas. In: ACOSTA, Alberto; MARTÍNEZ YÁNEZ, Esperanza. Derechos de la Naturaleza. Quito: AbyaYala, 2009. p. 31-37.

35 Nenhuma dessas dinâmicas afeta a qualidade de tais Povos como titulares de direitos, em especial ao direito à identidade cultural, embora possam afetar a convergência de seus interesses com a proteção do meio ambiente.

36 WONG, Marcela Torres. Natural resources, extraction and indigenous rights in Latin America: exploring the boundaries of environmental and State corporate crime in Bolivia, Peru and Mexico. London: Routledge, 2019; ZAREMBERG, Gisela; WONG, Marcela Torres. Participation on the edge: Prior consultation and extractivism in Latin America. Journal of Politics in Latin America, v. 10, n. 3 , p. 29-58, 2018; ANTKOWIAK, Thomas. Rights, ressources and rhetoric: indigenous peoples and te Inter-American Court. American Court, v. 35, n. 113, 2013. Disponível em: https://scholarship.law.upenn.edu/jil/vol35/iss1/3 Acesso em: 30 set. 2020.

37 Agradecemos ao Professor Cristobal Carmona, da Universidad Diego Portales de Chile, por nos atualizar nesta discussão e compartilhar suas próprias reflexões sobre o assunto, reflexões que são parte de tese de doutorado em desenvolvimento.
} 


\section{Normas constitucionais protetivas da Natureza}

\subsection{Direito Constitucional positivo}

A Constituição de 1988 também dispôs, de forma bastante abrangente, sobre a tutela do meio ambiente. Do ponto de vista substantivo, determinou que "Todos têm direito ao meio ambiente ecologicamente equilibrado", impondo ao Poder Público e à coletividade "o dever de defendê-lo e de preservá-lo para as presentes e futuras gerações” (art. 225, caput, CF). A proteção ambiental prevista nesse dispositivo abrange não apenas os espaços territoriais, a fauna, a flora e demais componentes. Ela alcança, ainda, a tutela dos animais contra tratamento cruel, a proteção da qualidade de vida, a preservação da "diversidade e da integridade do patrimônio genético", a proteção e restauração de todos os "processos ecológicos essenciais" aos ecossistemas, bem como vedação de práticas "provoquem a extinção de espécies" (art. 225, \ $1^{\circ}$, I, II, III, V, VII, CF). A esse ponto se voltará mais adiante.

A tais normas somam-se outras previstas em tratados internacionais de direitos humanos de que o Brasil é parte, que gozam de status supralegal (art. $5^{\circ}, \$ 2^{\circ}, \mathrm{CF}$ ), entre as quais se insere o princípio in dubio pro natura $^{38}$. Vale destacar, ainda, que o Direito Internacional dos direitos humanos pode funcionar, como já observado, como standard hermenêutico e como paradigma de validade de normas infraconstitucionais, por meio do controle de convencionalidade.

Do ponto de vista procedimental, destaca-se a exigência de prévio impacto ambiental para promoção de empreendimentos potencialmente danosos (art. 225, $\$ 1^{\circ}, \mathrm{IV}, \mathrm{CF}$ ), complementada por um conjunto de normas infraconstitucionais que tratam dos procedimentos de licenciamento ambiental entre outros instrumentos de polícia ambiental.

No plano institucional, a União, os Estados e os Municípios têm competência legislativa concorrente para tratar de temas ambientais, bem como competência administrativa comum para promover a proteção do meio ambiente, das florestas, da fauna e da flora (arts. 23, VI e VII; 24, VI, VII e VIII, CF). O Ministério Público tem entre as suas funções institucionais a proteção do meio ambiente. Compete à Defensoria Pública a proteção dos direitos humanos dos necessitados, entre os quais se inserem os grupos vulneráveis na perspectiva ambiental (art. 134, CF). Também a sociedade tem a responsabilidade pela proteção ao meio ambiente (art. 225, caput, CF). Há, igualmente, previsão de ações diretas integrantes do controle concentrado da constitucionalidade, de ações populares e de ações civis públicas que constituem instrumentos qualificados para a defesa do meio ambiente (art. 5, LXXIII; art. 102, “a” e \$1 $1^{\circ}$ : art. 129, III, CF).

Por fim, tal institucionalidade é complementada, em sede infraconstitucional, pelo Instituto Brasileiro do Meio Ambiente e dos Recursos Naturais Renováveis - IBAMA ${ }^{39}$, pelo Instituto Chico Mendes da Biodiversidade - $\mathrm{ICMBio}^{40}$, por batalhões policiais especializados em polícia ambiental, bem como por múltiplas instituições estaduais e municipais destinadas a funções semelhantes em seus respectivos âmbitos territoriais.

\footnotetext{
38 TRINDADE, Antônio Augusto Cançado. Direitos humanos e meio-ambiente: paralelo dos sistemas de proteção internacional. Porto Alegre: Sérgio Antônio Fabris, 1993; OLIVARES, Alberto. Contenido y desarrollo del principio in dubio pro natura. Hacia la protección integral del medio ambiente. Ius et Praxis, v. 3, n. 24, p. 619-650, 2018; BERMÚDEZ, Jorge. Fundamentos del Derecho Ambiental. Santiago: Ediciones Universitarias de Valparaíso, 2015.

39 Criado pela Lei n. 7.735/1989, compete ao IBAMA exercer o poder de polícia ambiental e executar ações das políticas nacionais de meio ambiente, bem como atuar no licenciamento, na fiscalização, no monitoramento e no controle ambiental, entre outras ações. 40 Criado pela Lei n. 11.516/2007, compete ao ICMBio, entre outros: executar ações da política nacional de unidades de conservação da natureza, incluindo a proposição, implantação, gestão, proteção, fiscalização e monitoramento das unidades de conservação instituídas pela União; executar as políticas relativas ao uso sustentável dos recursos naturais renováveis e ao apoio às populações tradicionais nas unidades de conservação de uso sustentável instituídas pela União; exercer o poder de polícia ambiental para a proteção de tais unidades de conservação.
} 


\subsection{Hermenêutica ecocêntrica}

Há, atualmente, um debate importante sobre a forma de interpretar normas de tutela da Natureza, segundo o qual elas podem envolver perspectivas: (i) antropocêntricas, que pregam a proteção ao meio ambiente como forma de tutela do próprio ser humano ${ }^{41}$; (ii) patocêntricas, que têm por objeto a tutela de animais sencientes; (iii) biocêntricas, que defendem a proteção a todos os seres vivos; e, finalmente, (iv) ecocêntricas, segundo as quais toda a Natureza, individual e coletivamente considerada, com todos os seus elementos, deve ser objeto de proteção ${ }^{42}$. Trata-se de debate que remete a discussões de ética ambiental ${ }^{43}$.

Assim, na perspectiva antropocêntrica, a proteção ambiental se justifica na medida da sua instrumentalidade para a proteção humana, já que um meio ambiente saudável constitui pré-condição para a fruição de direitos fundamentais tais como direito à vida, à saúde, à água, à alimentação adequada etc. Na perspectiva patocêntrica, os animais devem ser protegidos não porque são capazes de exercer a racionalidade, tal como os seres humanos, mas porque são capazes de sentir dor e sofrimento ${ }^{44}$. Segundo a perspectiva biocêntrica, toda forma de vida tem valor intrínseco, tem dignidade e, portanto, deve ser protegida independentemente de sua utilidade para os humanos ${ }^{45}$. Por fim, a visão ecocêntrica expressa a ideia de que todos os elementos da Natureza são essenciais para seus processos e compõem a sua integridade. Por essa razão, a Natureza deve ser compreendida como um bem jurídico autônomo, como um patrimônio da humanidade, a ser protegido em sua inteireza. A destruição de ecossistemas, animais e plantas não deve suscitar, apenas, compaixão, mas sim reflexões sobre questões de justiça ecológica e, portanto, sobre o direito de todos os seres (humanos e não humanos) a se desenvolverem e completarem, naturalmente, seu ciclo de vida ${ }^{46}$.

41 Para a inter-relação entre proteção ao meio ambiente e proteção aos direitos humanos, v. TRINDADE, Antônio Augusto Cançado. The parallel evolutions of international human rights protection and of environmental protection and the absence of restrictions upon the exercise of recognizes human rights. In: TRINDADE, Antônio Augusto Cançado; LEAL, César Barros. Human rights and environment. Fortaleza: Expressão Gráfica e Editora, 2017, p. 49-92.

42 As perspectivas biocêntricas e ecocêntricas relacionam-se ao movimento da Deep Ecology, que justamente reconhece que todos os bens da Natureza estão inter-relacionados, têm um valor e por isso devem ser protegidos. NAESS, Arne. The shallow and the deep, long-range ecology movement. A Summary. An Interdisciplinary Journal of Philosophy, v. 16, n. 1-4, 1973.

43 GUDYNAS, Eduardo. La senda biocéntrica: valores intrínsecos, derechos de la naturaleza y justicia ecológica. Tabula Rasa, n. 13, p. 45-71, jul./dez. 2010; MARTÍNEZ YÁNEZ, Esperanza; ACOSTA, Alberto. La Naturaleza entre la cultura, la biología y el derecho. Polis, Revista Latinoamericana, v. 13, n. 38, p. 623-627, 2014; SARLET, Ingo Wolfgang; FENSTERSEIFER, Tiago. Direito constitucional ecológico. 6. ed. São Paulo: Revista dos Tribunais, 2019; NAESS, Arne. The shallow and the deep, long-range ecology movement. A Summary. An Interdisciplinary Journal of Philosophy, v. 16, n. 1-4, 1973; NUSSBAUM, Martha C. Beyond. Compassion and humanity: justice for nonhuman animals. In: NUSSBAUM, Martha C. Frontiers of justice: disability, nationality, species membership. Cambridge: Harvard University Press, 2006. p. 324-407; SINGER, Peter. Animal liberation: new ethics for our treatment of animals, New York: Random House, 1975; FERREIRA, Fabíola; BOMFIM, Zulmira Áurea Cruz. Sustentabilidade Ambiental: visão antropocêntrica ou biocêntrica? AmbientalMENTEsustentable, v. 1, n. 9-10, 2010.

44 Martha Nussbaum observa que, assim como a justiça global requer a inclusão de grupos de pessoas historicamente excluídas (pobres, minorias religiosas, étnicas, raciais, mulheres etc.), é preciso voltar também os olhos para "outros animais sencientes com cujas vidas nossas próprias vidas estão inevitável e complexamente inter-relacionadas". Com esse objetivo, a autora propõe a teoria das capacidades ("the capabilities approach"), segundo a qual deve-se permitir a cada animal o desenvolvimento das capacidades que tem condições de desenvolver e, nessa medida, assegurar-lhes uma vida conforme com o tipo de dignidade compatível com a sua espécie. No que respeita à tutela do meio ambiente, a dignidade animal, segundo a autora, abrange necessariamente o respeito pela integridade do seu habitat. NUSSBAUM, Martha C. Beyond. Compassion and humanity: justice for nonhuman animals. In: NUSSBAUM, Martha C. Frontiers of justice: disability, nationality, species membership. Cambridge: Harvard University Press, 2006. p. 324-407.

45 NAESS, Arne. The shallow and the deep, long-range ecology movement. A Summary. An Interdisciplinary Journal of Philosophy, v. 16, n. 1-4, 1973. Trata-se de corrente que teria inspirado o reconhecimento dos direitos da Natureza pela Constituição do Equador (art. 71), primeira Constituição no mundo Ocidental a fazê-lo. GUDYNAS, Eduardo. La senda biocéntrica: valores intrínsecos, derechos de la naturaleza y justicia ecológica. Tabula Rasa, n. 13, p. 45-71, jul./dez. 2010. p. 51; MARTÍNEZ YÁNEZ, Esperanza; ACOSTA, Alberto. La Naturaleza entre la cultura, la biología y el derecho. Polis, Revista Latinoamericana, v. 13, n. 38, p. 623-627, 2014. p. 624.

46 A expressão justiça ecológica (fundada em uma visão biocêntrica) se opõe à concepção de justiça ambiental, que tem por foco a percepção antropocêntrica da importância de preservar bens ambientais dada sua relevância para os seres humanos. GUDYNAS, Eduardo. La senda biocéntrica: valores intrínsecos, derechos de la naturaleza y justicia ecológica. Tabula Rasa, n. 13, p. 45-71, jul./ dez. 2010. p. 60. 
De fato, o art. 225 da Constituição de 1988 comporta diversas formas de interpretação ${ }^{47}$. No entanto, por razões que serão abordadas no último tópico deste trabalho, optaremos por demonstrar que tal dispositivo permite a afirmação de uma visão ecocêntrica da tutela ambiental, que é aquela que confere maior efetividade e amplitude à proteção da Natureza.

Um primeiro argumento invocado em favor da visão ecocêntrica baseia-se em elemento literal de interpretação. Afirma-se que o art. 225 da Constituição previu que "Todos" têm direito a um meio ambiente saudável. Nessa linha, a expressão todos não limitaria tal direito apenas a animais humanos, nem mesmo a animais, e comportaria compreensão gramatical que poderia estendê-lo à integridade da Natureza ${ }^{48}$.

Entretanto, o argumento de maior peso em favor de uma abordagem ecocêntrica é aquele que busca compreender o art. 225, parágrafos e incisos, da Constituição, em seu conjunto. Segundo essa abordagem, tal artigo contemplou uma proteção ampla ao meio ambiente: citou diversos bens ambientais como objeto de tutela, como a fauna e a flora; vedou que se conferisse tratamento cruel aos animais (art. 225, $1^{\circ}$, VII, CF); aludiu à proteção do "patrimônio genético" (art. 225, 1, II, CF) e dos "processos ecológicos" necessários à preservação dos ecossistemas (art. 225, 1, I, CF). A proteção de "processos ecológicos" sugere o reconhecimento de valor não apenas aos elementos que compõem a Natureza, mas também aos processos que resultam da interação entre tais elementos, o que abrange seres vivos e não vivos. A Carta vedou, ainda, as práticas que "provoquem a extinção de espécies" e, quanto a elas, não condicionou tal vedação àquelas que têm utilidade para os humanos. Nessa medida, defende-se que o art. 225 da CF, em seu conjunto, aponta para a proteção da Natureza em sua integridade, como bem autônomo, como valor em si e que comporta, portanto, uma compreensão ecocêntrica ${ }^{49}$.

A adoção de uma interpretação ecocêntrica das normas de proteção ao meio ambiente pode ensejar uma relevante alteração de paradigma do ponto de vista hermenêutico porque implica a retirada dos animais humanos do centro do sistema jurídico e a atribuição de tal centralidade à própria Natureza. Esse reconhecimento do valor da integridade da Natureza se compatibiliza com cosmovisões indígenas que atribuem a elementos vivos e não vivos significados e valores específicos, culturais e espirituais, a serem preservados. Há, nessa medida, convergência entre a hermenêutica intercultural e a hermenêutica ecocêntrica.

Destaca-se, ainda, em matéria de proteção à Natureza, a relevância dos princípios da precaução e da prevenção, como normas orientadoras de toda e qualquer decisão que envolva riscos ambientais ou a mitigação de efeitos adversos ao meio ambiente (art. 225, \ $1^{\circ}$, I, II e IV; art. 196, CF). Nesse sentido, de acordo com tais princípios, deve-se agir, preventivamente, para evitar danos já conhecidos ou que podem ser previstos (prevenção). Além disso, devem-se adotar medidas de proteção de danos ambientais inclusive quando não houver certeza científica quanto à possibilidade (precaução). Em caso de dúvida quanto ao potencial danoso de um empreendimento, de um produto ou serviço, ele deve ser evitado. Deve-se, ainda, optar pela medida mais segura e potencialmente menos adversa ao meio ambiente, conforme o estado atual do conhecimento. Isso ocorre porque o dano ambiental, uma vez produzido, é de difícil recuperação, de forma que a ênfase deve estar nas ações de prevenção ${ }^{50}$.

\footnotetext{
47 O dispositivo tem inspirado, inclusive, proposta de reformulação do princípio da dignidade humana, para incorporar-lhe o reconhecimento de um mínimo existencial ecológico. SARLET, Ingo Wolfgang; FENSTERSEIFER, Tiago. Algumas notas sobre a dimensão ecológica da dignidade da pessoa humana e sobre a dignidade da vida em geral. Revista Direito e Sociedade, v. 3, n. 1, p. 69-94, 2015. p. 69.

48 GONÇALVES, Daniel Diniz; TÁRREGA, Maria Cristina Vidotte Blanco. Giro ecocêntrico: do Direito Ambiental ao Direito Ecológico. Revista Direito Ambiental e sociedade, v. 8, n. 1, 2018, pp. 138-157.

49 Em sentido semelhante: SARLET, Ingo Wolfgang; FENSTERSEIFER, Tiago. Algumas notas sobre a dimensão ecológica da dignidade da pessoa humana e sobre a dignidade da vida em geral. Revista Direito e Sociedade, v. 3, n. 1, p. 69-94, 2015. p. 86-88.

50 SCHMIDT, Cíntia. Princípios de direito ambiental. Interesse Público, ano 13, n. 69, p. 187-207, 2011; ZANELLA, Tiago Vinicius. A aplicação da precaução no direito internacional do ambiente: uma análise à luz da proteção do meio marinho. Revista Internacional de Direito Ambiental, v. 5, n. 13, jan./abr. p. 307-332, 2016; THOMÉ, Romeu; LAGO, Talita Martins Oliveira. Barragens de rejeitos da mineração: o princípio da prevenção e a implementação de novas alternativas. Revista de Direito Ambiental, v. 85, p. 17-39, jan./mar. 2017; FERNANDES, Patrícia Vieira dos Santos. A importância dos princípios da precaução e da prevenção na busca do desenvolvi-
} 


\section{Os Povos Indígenas e a proteção à Natureza no Direito Internacional dos direitos humanos}

\subsection{Direito à identidade cultural no Direito Internacional dos direitos humanos}

O direito à identidade cultural vem sendo extensamente reconhecido e desenvolvido em âmbito internacional, bem como regional, no último caso, principalmente, pela Corte Interamericana de Direitos Humanos $(\text { Corte IDH })^{51}$. Em âmbito universal, se baseia em distintos instrumentos internacionais como a Declaração Universal dos Direitos Humanos, o Pacto de Direitos Civis e Políticos (artigos 22 e 27), o Pacto de Direitos Econômicos, Sociais e Culturais (artigo 27), a Convenção para Salvaguarda do Patrimônio Cultural Imaterial, a Convenção de Paris (2003), a Declaração Universal da UNESCO sobre Identidade Cultural (2001), a Declaração sobre os Direitos das Pessoas Pertencentes a Minorias Nacionais ou Étnicas, Religiosas e Linguísticas $(1992)^{52}$.

No âmbito interamericano, tal direito se fundamenta, genericamente, nos arts. 1.1. e 2 da Convenção Americana dos Direitos Humanos (CADH); especificamente nos direitos à la vida (art. 4.1), à integridade pessoal (art. 5), à propriedade, aos territórios quanto aos Povos Indígenas, à subsistência (art. 21), à igualdade e à não discriminação (art. 24), bem como nos direitos econômicos, sociais e culturais (artigo 26) previstos na Convenção Americana dos Direitos Humanos (CADH). Tem por base ainda o Convenio 169 de la OIT (artigos 4.1, 7.1, 15.1 y 23). Além disso, a Declaração das Nações Unidas dos Direitos dos Povos Indígenas (DNUDPI) e a Declaração Americana de Direitos dos Povos Indígenas (DADPI), ainda que não vinculantes, servem igualmente de base para o seu reconhecimento ${ }^{53}$.

No âmbito da Corte IDH, o direito à identidade cultural é reconhecido como um direito de natureza individual e coletiva, de titularidade das comunidades tradicionais, dos povos indígenas e dos povos tribais (a exemplo dos quilombolas), bem como de seus respectivos membros ${ }^{54}$. As decisões da Corte a respeito desse direito e suas implicações podem ser sintetizadas nos seguintes termos:

mento sustentável. LéC - Revista de Administração Pública e Política, n. 156, jun. 2011. p 33-34. Em sentido contrário, entendendo que o princípio da precaução muitas vezes enseja uma interferência excessiva do Judiciário, gera paralisia e produz decisões desproporcionais: REIS, José Augusto; LAMARE, Júlia de. O princípio da precaução e a intervenção judicial em processos de licenciamento ambiental de empreendimentos de energia. In: STEINDORFER, Fabriccio (coord). Direito da energia elétrica. Curitiba: Juruá, 2017. p. 191-208.

51 Corte IDH. "Caso Bámaca Velásquez vs. Guatemala” (Fundo). Sentença de 25 de novembro de 2000; Corte IDH "Comunidad (Sumo) Awas Tigni Vs. Nicaragua” (2001). Corte IDH, "Caso Masacre Plan de Sánchez vs. Guatemala” (2004). Corte IDH, "Caso Comunidad Indígena Moiwana vs. Surinam” (2005), Corte IDH, “Caso Comunidad Indígena Yakye Axa” vs. Paraguay (2006). Corte IDH, "Caso de la Comunidad Indígena Sawhoyamaxa vs. Paraguay (2006). Corte IDH, "Caso del Pueblo Saramaka vs. Surinam" (2007). Corte IDH, "Comunidad indígena Xákmok Kásek vs. Paraguay” (2010). Corte IDH, "Pueblo Indígena Sarayaku vs. Ecuador” (2012). Corte IDH, "Caso Norín Catrimán y otros (dirigentes, miembros y activista del pueblo indígena mapuche) vs. Chile” (2014). Corte IDH, "Caso Comunidad Garifuna de Punta Piedra y sus miembros vs. Honduras" (2015). Corte IDH, "Caso Pueblo Indígena Xucuru y sus miembros vs. Brasil" (2018). CORTE INTERAMERICANA DE DIREITOS HUMANOS. "Caso comunidades indígenas miembros de la asociación Lhaka Honhat (nuestra tierra) vs. Argentina” (Fundo, Reparações e Custas). Sentença de 6 de fevereiro de 2020.

52 DEL CARPIO, Columba. Pluralismo Jurídico, derecho bumano a la identidad cultural y globalización. Navarra: Editorial Aranzadi SA, 2014; OLIVARES, Alberto. El derecho a la identidad cultural. In: AGUILAR, Gonzalo (coord.). Nuevos derechos para una nueva Constitución. Valencia: Tirant Lo Blanch, 2019. p. 83.

53 A Corte IDH utiliza, em seu processo decisório, as doutrinas hermenêuticas do "controle de convencionalidade" e a denominada "interpretação evolutiva", com base nas quais articula fontes vinculantes e não vinculantes de Direito Internacional, sob o conceito de "corpus iuris" de direitos humanos. Trata-se de questão objeto de extenso debate, que excede o escopo deste trabalho. Sobre o tema e registrando as evoluções mais recentes da Corte, FAUNDES, Juan Jorge; CARMONA, Cristobal; SILVA, Pedro Pablo. La Corte Interamericana de Derechos Humanos. Hermeneutica del derecho al medio ambiente sano, a la identidad cultural y a la consulta, a la luz de la sentencia "Lhaka Honhat (nuestra tierra) vs. Argentina (2020)". Revista Brasileira de Políticas Públicas, v. 11, n. 2, 2020.

54 Corte IDH. "Caso del Pueblo Indígena Kichwa de Sarayaku vs. Ecuador" (2012), par. 213. 
1. O direito à identidade cultural é um direito de base religiosa, cultural, espiritual, imaterial, ligado essencialmente às terras, territórios e aos recursos naturais das áreas em que tais povos habitam ${ }^{55}$.

2. Tal direito é inalienável e se expressa em conexão com o direito à vida dos Povos Indígenas e coma proteção do direito à propriedade, uso e gozo de suas terras, imprescindível para assegurar sua sobrevivência física e cultural, bem como o desenvolvimento e a continuidade de sua cosmovisão ${ }^{56}$.

3. O Estado tem um dever especial de diligência que lhe impõe resguardar a sobrevivência de tais povos e adotar medidas efetivas para proteção ao direito à identidade cultural, em todas as suas dimensões ${ }^{57}$.

4. Os direitos dos povos indígenas devem ser compreendidos à luz da cosmovisão indígena e dos elementos expressos em suas vivências e culturas — especialmente em sua dimensão intangível ou imateria $1^{58}$. Nesse sentido, demandam e ao mesmo tempo ensejam o desenvolvimento de uma hermenêutica intercultural ${ }^{59}$.

5. O Estado deve assegurar a participação efetiva dos povos indígenas na decisão acerca de todo e qualquer plano de desenvolvimento, investimento, exploração ou extração que se realize em seu território, por meio de consulta aos povos interessados ${ }^{60}$. Esse direito deriva do direito de propriedade de tais povos ${ }^{61}$. Em projetos com "impacto significativo sobre o direito ao uso e gozo de seus territórios ancentrais", o Estado deve buscar "o consentimento de tais povos" ${ }^{2}$.

6. Projetos de investimento em território indígena devem ser objeto de estudo prévio de impacto social e ambiental ${ }^{63}$

Em síntese, portanto, no que respeita aos Povos Indígenas, a proteção à identidade cultural se relaciona à proteção à própria vida e subsistência de tais povos. Implica a necessidade de interpretar comportamentos e direitos à luz da sua cultura e das suas práticas. Gera direitos procedimentais de participação e de estudos

55 Corte IDH. "Caso Comunidad Indígena Yakye Axa vs. Paraguay”, (2005), par.135.

56 Corte IDH. "Caso del Pueblo Indígena Kichwa de Sarayaku vs. Ecuador” (2012), par. 40.

57 Corte IDH. "Caso Pueblo Indígena Xucuru vs. Brasil” (2018), párrs. 93-194.

58 Corte IDH. "Caso del Pueblo Indígena Kichwa de Sarayaku vs. Ecuador” (2012), par. 213; e Corte IDH. "Caso Norín Catrimán y otros (dirigentes, miembros y activista del pueblo indígena mapuche) vs. Chile” (2014), par. 357. FAUNDES, Juan Jorge. Consulta indígena y centrales de generación hidroeléctrica de menos de 3MW: desregulación riesgosa, a la luz del derecho fundamental a la identidad cultural de los pueblos indígenas. In: BOZZO, Sebastián; REMESEIRO, Rebeca; ESIS, Ivette (ed.). Memorias III Congreso Internacional de Regulación y Consumo. Santiago: RIL, Universidad Autónoma de Chile, 2020. p. 359-398.

59 FAUNDES, Juan Jorge. Consulta indígena y centrales de generación hidroeléctrica de menos de 3MW: desregulación riesgosa, a la luz del derecho fundamental a la identidad cultural de los pueblos indígenas. In: BOZZO, Sebastián; REMESEIRO, Rebeca; ESIS, Ivette (ed.). Memorias III Congreso Internacional de Regulación y Consumo. Santiago: RIL, Universidad Autónoma de Chile, 2020. p. 359-398; FAUNDES, Juan Jorge. El derecho fundamental a la identidad cultural de los pueblos indígenas: un derecho-matriz y filtro hermenéutico para las constituciones de América Latina: la justificación. Revista Brasileira de Políticas Públicas, v. 9, n. 2, ago. 2019. p. 517; FAUNDES PEÑAFIEL, Juan Jorge; RAMÍREZ, Silvina. Introducción. El derecho a la identidad cultural, horizontes plurales latinoamericanos. In: FAUNDES, Juan Jorge; RAMÍREZ, Silvina (org.). Derecho fundamental a la identidad cultural, abordajes plurales desde América Latina. Santiago: RIL, Universidad Autónoma de Chile, 2020; RAMÍREZ, Silvina (org.). Derecho fundamental a la identidad cultural, abordajes plurales desde América Latina. Santiago: RIL, Universidad Autónoma de Chile, 2020.

60 CORTE INTERAMERICANA DE DIREITOS HUMANOS. "Caso comunidades indígenas miembros de la asociación Lhaka Honhat (nuestra tierra) vs. Argentina" (Fundo, Reparações e Custas). Sentença de 6 de fevereiro de 2020. p. 169-185; Corte IDH, "Caso del Pueblo Saramaka vs. Surinam" (2007), par. 133. FAUNDES, Juan Jorge; CARMONA, Cristobal; SILVA, Pedro Pablo. La Corte Interamericana de Derechos Humanos. Hermeneutica del derecho al medio ambiente sano, a la identidad cultural y a la consulta, a la luz de la sentencia "Lhaka Honhat (nuestra tierra) vs. Argentina (2020)". Revista Brasileira de Políticas Públicas, v. 11, n. 2, 2020; CARMONA, Cristóbal. Consentimiento Libre Previo e Informado en el contexto de proyectos extractivos en territorio indígena ¿Regla general y Derecho Consuetudinario Internacional? Revista Brasileira de Políticas Públicas, v. 9, n. 3, p. 372-399, 2019; CARMONA, Cristóbal. Tomando los derechos colectivos en serio: el derecho a consulta previa del convenio 169 de la OIT y las instituciones representativas de los Pueblos indígenas. Ius et Praxis, ano 19, n. 2, p. 301-334, 2013.

${ }_{61}$ Corte IDH, "Caso del Pueblo Saramaka vs. Surinam” (2007), pars. 121 y 122.

62 Corte IDH, "Caso del Pueblo Saramaka vs. Surinam” (2007), pars. 136.

63 Corte IDH, "Caso del Pueblo Saramaka vs. Surinam" (2007), pars. 129. No mesmo sentido, v.: Corte IDH. "Caso del Pueblo Indígena Kichwa de Sarayaku vs. Ecuador" (2012), par. 176; Corte IDH, "Caso Comunidad Garifuna de Punta Piedra y sus miembros vs. Honduras" (2015), pars. 215 e ss.; Corte IDH. “Comunidad Garifuna Trinnfo de la Cruz y sus miembros vs. Honduras”, pars. 154 e ss. 
prévios de impacto, quanto a empreendimentos que possam afetá-los, incluindo os efeitos de caráter cultural ou intangível. Enseja um dever estatal de proteção, que impõe ao Estado adotar medidas e instituições adequadas e insuficientes a tal tutela. ${ }^{64}$

\subsection{Direito ao meio ambiente no Direito Internacional dos direitos humanos ${ }^{65}$}

O direito a um meio ambiente saudável vem sendo afirmado em diversas normas de Direito Internacional de ordem universal e regional. Essas normas têm por objeto a proteção ao meio ambiente propriamente, tal proteção em conexão com direitos humanos ou, ainda, a promoção da ideia de desenvolvimento sustentável. No âmbito universal, podem-se mencionar: a Declaração de Estocolmo sobre o Meio Ambiente Humano (1972) $)^{66}$, a Carta da Natureza (1982) ${ }^{67}$, a Declaração do Rio sobre Meio Ambiente e Desenvolvimento $(1992)^{68}$, a Convenção sobre a Diversidade Biológica (1992) ${ }^{69}$, a Declaração de Johannesburgo sobre Desenvolvimento Sustentável (2002) e o Plano de Aplicação das Decisões da Cúpula Mundial sobre o Desenvolvimento Sustentável (2002) ${ }^{70}$ e a Agenda 2030 para o Desenvolvimento Sustentável: Transformar Nosso Mundo (2015) ${ }^{71}$. Merecem referência, ainda, três documentos internacionais patrocinados pela Organização das Nações Unidades que procuram enfrentar os desafios decorrentes das mudanças climáticas: a Convenção Quadro sobre Mudança Climática (1992) ${ }^{72}$, o Protocolo de Kyoto (1997) ${ }^{73}$ e o Acordo de Paris (2015) ${ }^{74}$.

Em âmbito regional, são instrumentos relevantes sobre o tema: a Carta da Organização dos Estados Americanos $(\mathrm{OEA})^{75}$, que prevê a obrigação dos Estados de alcançar o desenvolvimento integral de seus povos (arts. 30, 31, 33 e 34); a Convenção Americana de Direitos Humanos (CADH) (1969) ${ }^{76}$, quanto ao

\footnotetext{
${ }^{64}$ De acordo com James Anaya, a consulta prévia é obrigatória "sempre que uma decisão possa afetar aos povos indígenas em modos não percebidos por outros indivíduos da sociedade, [o que ocorre] quando a decisão se relaciona com os interesses ou as condições específicas de determinados povos indígenas”. O autor observa, ainda, que os Estados devem avaliar previamente as medidas legislativas ou administrativas que venham a ser propostas, em especial aquelas relativas à extração de recursos naturais, para determinar a necessidade de iniciar processos de consulta que antecedam a adoção de tais medidas. ANAYA, James. Principios internacionales aplicables a la consulta en relación con la reforma constitucional en materia de derechos de los pueblos indigenas en Chile. Disponível em: https://www.ohchr.org/Documents/Issues/IPeoples/SR/InformeConsultaChile.pdf Acesso em: 26 set. 2020. p. 23.

65 Optamos por tratar da matéria no Direito Internacional, tendo como ponto de partida as fontes normativas articuladas pela Corte IDH no tema e enfatizando sua jurisprudência, já que o Brasil se submeteu à sua jurisdição. A exceção, nesse item, está na referência aos documentos relacionados às mudanças climáticas, que não estão, ainda, explorados em sua jurisprudência.

66 ORGANIZAÇÃO DAS NAÇÕES UNIDAS. Declaração de Estocolmo sobre o ambiente bumano - 1972. Disponível em: http:/ /www. direitoshumanos.usp.br/index.php/Meio-Ambiente/declaracao-de-estoco000000000000000000lmo-sobre-o-ambiente-humano. html Acesso em: 26 set. 2020.

67 ORGANIZAÇÃO DAS NAÇÕES UNIDAS. Carta Mundial da Naturez̨a. Disponível em: https://www.dh-cii.eu/0_content/ investigao/files_CRDTLA/convencoes_tratados_etc/carta_mundial_da_natureza_de_28_de_outubro_de_1982.pdf Acesso em: 26 set. 2020.

68 ORGANIZAÇÃO DAS NAÇÕES UNIDAS. Declaração do Rio sobre Meio Ambiente e Desenvolvimento. Disponível em: https:// cetesb.sp.gov.br/proclima/wp-content/uploads/sites/36/2013/12/declaracao_rio_ma.pdf Acesso em: 26 set. 2020.

69 ONU. Conferência das Nações Unidas sobre Meio Ambiente e Desenvolvimento, Rio de Janeiro, 3-14 de junho de 1992. Adotada no Rio de Janeiro, República Federativa de Brasil, em 5 de junho de 1992.

70 ORGANIZAÇÃO DAS NAÇÕES UNIDAS. Declaração de Johannesburgo sobre o Desenvolvimento Sustentável. Disponível em: https://cetesb.sp.gov.br/proclima/wp-content/uploads/sites/36/2013/12/decpol.pdf Acesso em: 26 set. 2020.

71 Resolução 70/1 de la Assembleia Geral das Nações Unidas, 25 de setembro de 2015. Doc. ONU A/RES/70/1.

72 ORGANIZAÇÃO DAS NAÇÕES UNIDAS. Convenção-Marco das Nações Unidas sobre Mudança do Clima (CMNUCC). Disponível em: http://www.mpf.mp.br/atuacao-tematica/sci/normas-e-legislacao/tratados/convencoes-meio-ambiente/convencao-quadrodas-nacoes-unidas-sobre-mudanca-do-clima.pdf/view Acesso em: 26 set. 2020.

73 ORGANIZAÇÃO DAS NAÇÕES UNIDAS. Protocolo de Kyoto da Convenção-Marco das Nações Unidas sobre Mudança do Clima. Disponível em: http://www.direitoshumanos.usp.br/index.php/Meio-Ambiente/protocolo-de-quioto-a-convencao-quadro-dasnacoes-unidas-sobre-mudanca-do-clima.html Acesso em: 26 set. 2020.

74 ORGANIZAÇÃO DAS NAÇÕES UNIDAS. Acordo de Paris. Disponível em: https://www.undp.org/content/dam/brazil/ docs/ODS/undp-br-ods-ParisAgreement.pdf Acesso em: 26 set. 2020.

75 OEA. Assembleia Geral, Carta da Organização dos Estados Americanos, adotada em Bogotá em 30 de abril de 1948.

76 OEA. Conferência Especializada Interamericana sobre Direitos Humanos. Convenção Americana de Direitos Humanos, adotada em São José da Costa Rica, em 22 de novembro de 1969.
} 
dever estatal de implementação progressiva de direitos sociais, econômicos e culturais (art. 26); e o Protocolo de São Salvador (1988), que afirma o direito de toda pessoa a viver em um meio ambiente sadio (art. 11). Além deles, a Corte IDH considera, no que se refere aos Povos Indígenas, que o direito ao meio ambiente saudável é tutelado pela Convenção 169 da OIT (arts. 4 1, 7º, 3 e 4 entre outros) e pela Declaração das Nações Unidas sobre os Direitos dos Povos Indígenas (art. 29) 77.

No que respeita ao reconhecimento de um valor intrínseco ao meio ambiente, vale mencionar que a Carta da Natureza (1982) ${ }^{78}$ afirma que: "Toda forma de vida é única e merece ser respeitada, qualquer que seja a sua utilidade para o homem". Na mesma linha, o preâmbulo da Convenção sobre Diversidade Biológica (1992) refere-se "ao valor intrínseco da diversidade biológica e dos valores ecológico, genético, social, econômico, científico, educacional, cultural, recreativo e estético da diversidade biológica e de seus componentes", bem como reconhece que a sua conservação é "uma preocupação comum à humanidade". Por fim, no âmbito do direito comparado, a Constituição do Equador de 2008, de forma pioneira, reconheceu expressamente a Natureza como sujeito de direitos (art. 71) ${ }^{79}$.

No que respeita à jurisprudência da Corte IDH, dois casos se destacam quanto à justificação, o reconhecimento e as implicações do direito ao meio ambiente saudável: a Opinião Consultiva OC-23/1780 e o caso Lhaka Honhat de 2020 ${ }^{81}$. Na Opinião Consultiva OC-23/17, a Corte assinalou que o direito a um meio ambiente saudável constitui um direito autônomo, com base no art. 11 do Protocolo de São Salvador, e, simultaneamente, um direito derivado de outros direitos humanos, como o direito à vida ou à integridade pessoal $^{82}$. Como direito autônomo, assinalou que sua proteção incide sobre todos os elementos componentes do ambiente, "tais como bosques, mares, rios e outros, como interesses jurídicos em si mesmos, ainda que não haja certeza ou evidência de risco para pessoas individuais" "83. Observou que tal direito impõe a proteção da Natureza, não apenas por sua "utilidade" ou por seus "efeitos" sobre os seres humanos, mas "por

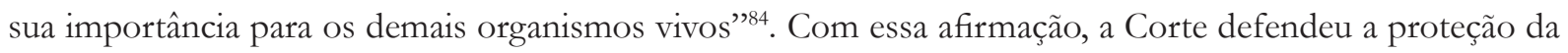
Natureza e de seus componentes como "bens em si”, por seu valor intrínseco, e não por serem instrumentais à proteção de interesses humanos. Nesses termos, aproximou-se da ideia da Natureza como "sujeito de direitos" ${ }^{\$ 5}$. Por fim, explicitou que danos ambientais podem ensejar a violação de outros direitos humanos ${ }^{86}$.

O caso Associação Lhaka Honhat v. Argentina (2020), por sua vez, envolvia o desenvolvimento de ativi-

\footnotetext{
ONU. Asambleia Geral. Declaração das Nações Unidas sobre Direitos dos Povos Indígenas, adotada em Nova Iorque, em 13 de setembro de 2007.

78 ORGANIZAÇÃO DAS NAÇÕES UNIDAS. Carta Mundial da Naturez̧a. Disponível em: https://www.dh-cii.eu/0_content/ investigao/files_CRDTLA/convencoes_tratados_etc/carta_mundial_da_natureza_de_28_de_outubro_de_1982.pdf Acesso em: 26 set. 2020.

79 Constituição da República do Equador: "Art. 71. A natureza ou Pacha Mama, onde se reproduz e se realiza a vida, tem direito a que se respeite integralmente a sua existência e a manutenção e regeneração de seus ciclos vitais, estrutura, funções e processos evolutivos".

80 CORTE INTERAMERICANA DE DIREITOS HUMANOS. Opinião Consultiva OC-23/17, "Solicitada por la República de Colombia sobre medio ambiente y derechos humanos", de 15 de novembro de 2017.

81 CORTE INTERAMERICANA DE DIREITOS HUMANOS. "Caso comunidades indígenas miembros de la asociación Lhaka Honbat (nuestra tierra) vs. Argentina” (Fundo, Reparações e Custas). Sentença de 6 de fevereiro de 2020.

82 CORTE INTERAMERICANA DE DIREITOS HUMANOS. Opinião Consultiva OC-23/17, "Solicitada por la República de Colombia sobre medio ambiente y derechos humanos", de 15 de novembro de 2017. p. 62-63.

83 CORTE INTERAMERICANA DE DIREITOS HUMANOS. Opinião Consultiva OC-23/17, "Solicitada por la República de Colombia sobre medio ambiente y derechos humanos", de 15 de novembro de 2017. p. 62.

84 CORTE INTERAMERICANA DE DIREITOS HUMANOS. Opinião Consultiva OC-23/17, "Solicitada por la República de Colombia sobre medio ambiente y derechos humanos", de 15 de novembro de 2017. p. 62.

85 PEÑA, Mario. La revolución de los derechos humanos ambientales y de los derechos de la naturaleza. 2018. Disponível em: https:// derecho. ucr.ac.cr/Posgrado/derecho-ambiental/la-revolucion-de-los-derechos-humanos-ambientales-y-de-los-derechos-de-la-naturaleza/. Acesso em: 30 set. 2020; FAUNDES, Juan Jorge; CARMONA, Cristobal; SILVA, Pedro Pablo. La Corte Interamericana de Derechos Humanos. Hermeneutica del derecho al medio ambiente sano, a la identidad cultural y a la consulta, a la luz de la sentencia "Lhaka Honhat (nuestra tierra) vs. Argentina (2020)". Revista Brasileira de Políticas Públicas, v. 11, n. 2, 2020.

86 CORTE INTERAMERICANA DE DIREITOS HUMANOS. Opinião Consultiva OC-23/17, "Solicitada por la República de Colombia sobre medio ambiente y derechos bumanos", de 15 de novembro de 2017. p. 64.
} 
dades agropecuárias degradantes por terceiros, com contaminação da água, desertificação do solo, consumo (por animais) dos alimentos necessários à subsistência indígena, supressão de espécies utilizadas para fins medicinais e comprometimento da biodiversidade necessária ao desenvolvimento de práticas ancestrais ${ }^{87}$. Em tais circunstâncias, a Corte IDH reconheceu a ocorrência de violação ao direito ao meio ambiente saudável e, em virtude dela, a ameaça ou o comprometimento dos direitos dos Povos Indígenas às suas fontes de alimento tradicionais, à água e à identidade cultural.

A decisão teve por base os fundamentos invocados no julgamento da OC-23/17, bem como a violação ao artigo 26 da Convenção Americana de Direitos Humanos (CADH), que estabelece o dever estatal de implementação progressiva de direitos sociais, econômicos e culturais. Afirmou, ainda, o descumprimento, pelo Estado, do seu dever de assegurar e de adequar suas normas internas aos direitos previstos na CADH (art. 1.1 e 2), entre os quais o direito dos Povos Indígenas a seus territórios (art. 21), à igualdade e à não discriminação (art. 24). E reconheceu a ocorrência de violação à Convenção 169 da OIT, no que respeita à obrigação de adotar medidas especiais voltadas à proteção da cultura, dos recursos naturais e do meio ambiente de que dependem os Povos Indígenas (arts. 4.1, 7.1, 15 e 23) ${ }^{88}$.

Por fim, assinalou que o dever estatal de proteção ao meio ambiente deve observar um standard de "devida diligência" e, portanto, incluir: (i) o respeito ao princípio da precaução; (ii) a regulação, supervisão e fiscalização de atividades capazes de produzir dano ambiental; (iii) o requerimento de estudos de impacto ambiental; (iv) o estabelecimento de planos de contingência e de mitigação, para os casos de ocorrência de dano ambiental. ${ }^{89}$

\section{Povos Indígenas e Natureza: pontos de convergência e tutela recíproca}

Estabelecidos os regimes jurídicos e as principais possibilidades hermenêuticas a que se sujeitam a tutela dos Povos Indígenas e a proteção da Natureza, passamos a examinar suas zonas de interseção. Com isso, procuramos compreender as contribuições que tais Povos e seu regime de proteção podem oferecer para a defesa do meio ambiente, bem como avaliar em que medida a tutela da Natureza pode igualmente reforçar os sistemas de proteção dos Povos Indígenas.

\subsection{A contribuição dos Povos Indígenas para a proteção da Natureza}

O papel dos Povos Indígenas para a proteção à Natureza pode ser compreendido a partir de três perspectivas: (i) sua presença e o regime jurídico que lhes é aplicável garantem uma maior efetividade à proteção ambiental, (ii) suas práticas promovem uma ressignificação do valor da Natureza que reforça a sua preservação; e (iii) as normas que os protegem asseguram mecanismos de participação e de diálogo que favorecem a tutela do meio ambiente.

Em relação à maior efetividade da proteção ambiental, não é segredo que as terras indígenas, assim como as áreas caracterizadas como unidades de conservação, apresentam percentuais muito inferiores de desmatamento ${ }^{90}$.

\footnotetext{
CORTE INTERAMERICANA DE DIREITOS HUMANOS. "Caso comunidades indígenas miembros de la asociación Lhaka Honbat (nuestra tierra) vs. Argentina” (Fundo, Reparações e Custas). Sentença de 6 de fevereiro de 2020. p. 282-284.

88 CORTE INTERAMERICANA DE DIREITOS HUMANOS. "Caso comunidades indígenas miembros de la asociación Lhaka Honhat (nuestra tierra) vs. Argentina” (Fundo, Reparações e Custas). Sentença de 6 de fevereiro de 2020. p. 247.

89 CORTE INTERAMERICANA DE DIREITOS HUMANOS. "Caso comunidades indigenas miembros de la asociación Lhaka Honbat (nuestra tierra) vs. Argentina” (Fundo, Reparações e Custas). Sentença de 6 de fevereiro de 2020. p. 208-209. Sobre os princípios pro natura e da precaução, OLIVARES, Alberto. Contenido y desarrollo del principio in dubio pro natura. Hacia la protección integral del medio ambiente. Ius et Praxis, v. 3, n. 24, p. 619-650, 2018; BERMÚDEZ, Jorge. Fundamentos del Derecho Ambiental. Santiago: Ediciones Universitarias de Valparaíso, 2015.

90 BARAGWANATH, Kathryn; BAYL, Ella. Collective property rights reduce deforestation in the Brazilian Amazon. PNAS
} 
Em primeiro lugar, o Brasil possui grandes extensões de floresta. Dada tal extensão, o monitoramento do que ocorre em todas as áreas de floresta é difícil. Demandaria enorme contingente de servidores. Trata-se, ainda, muitas delas, de áreas de difícil acesso, de mata cerrada, sem estradas, banhadas por rios apenas parcialmente navegáveis. Por essa razão, a presença do Estado é baixa e onerosa. As florestas são, contudo, o habitat natural dos Povos Indígenas. A sua presença e locomoção em tais áreas é parte do seu modo de viver. Nessa medida, tal presença os transforma em "defensores da floresta", já que, tendo conhecimento da existência de invasores e de atividades ilícitas em suas áreas, podem fazer soar o primeiro alarme e levar tal fato ao conhecimento das autoridades.

De modo geral, tais Povos também exercem, por seus próprios meios, a defesa de seus territórios. Do mesmo modo, a institucionalidade que protege os indígenas penetra, em alguma medida, nas florestas. Bases de Proteção Etnoambiental, barreiras sanitárias e equipes de saúde asseguram a presença de servidores estatais, que levam ao conhecimento das autoridades eventuais invasões e atividades violadoras do meio ambiente. Portanto, a presença de Povos Indígenas e das instituições voltadas à proteção e promoção de seus direitos são um elemento de proteção da Natureza.

Também o regime jurídico especial a que se submetem as suas áreas são um mecanismo de reforço à proteção ambiental. Em primeiro lugar, o aproveitamento dos recursos hídricos e a pesquisa e a lavra das riquezas minerais em terras indígenas dependem da oitiva de suas comunidades e da autorização do Congresso Nacional (art. 231, CF). Além disso, as terras indígenas são bens públicos da União, gravados com usufruto perpétuo em favor de tais Povos. No contexto brasileiro, parte substancial dos desmatamentos relacionam-se a processos de grilagem de terras públicas, que observam as seguintes etapas: retirada das árvores de maior valor (madeira) para comercialização, queimada da área para remoção da vegetação subsistente, instalação de gado de modo a marcar a sua ocupação pelo possuidor, com o propósito final de obter a regularização da propriedade, em seu próprio nome, mediante pagamento de preço inferior ao de mercado ao Poder Público ${ }^{91}$.

De fato, leis aprovadas em governos de todos os vieses ideológicos têm promovido tais regularizações ao longo do tempo e funcionam como um verdadeiro incentivo à grilagem de terras públicas ${ }^{92}$. Tal incentivo não está presente, contudo, em terras indígenas, já que elas não se sujeitam à regularização ou transferência de propriedade para particulares. Há, portanto, menor estímulo à invasão de tais terras por parte de grileiros que desejem implementar o ciclo completo antes descrito. Vale mais a pena, para tais atores, investir em terras públicas não destinadas ${ }^{93}$. De todo modo, é importante reconhecer a presença relevante da mineração ilegal em terras indígenas, muitas vezes com o uso de mercúrio, gerando dano não apenas ao meio ambiente, mas à saúde da população e à preservação de seu modo de vida tradicional ${ }^{94}$.

Quanto à contribuição das práticas indígenas para a proteção da Natureza, como já antecipado, a subsistência indígena, sua reprodução física e cultural, dependem da integridade do ecossistema que habitam e da higidez de seus processos ecológicos. A poluição de um rio ou a contaminação do solo podem comprometer de forma irreversível suas práticas e sua própria subsistência. Além disso, a cultura e a cosmovisão de tais Povos atribuem à Natureza e a seus elementos uma conotação espiritual e transcendente, e não o valor inferior de

Latest Articles, jul. 2020. Disponível em: https://www.amazoniasocioambiental.org/wp-content/uploads/2020/08/10.1073@ pnas.1917874117.pdf. Acesso em 30 set. 2020; HUMAN RIGHTS WATCH. Máfias do Ipê. Nova York: HRW, 2019. Disponível em: https://www.hrw.org/pt/report/2019/09/17/333886 Acesso em: 9 fev. 2020.

91 BARROSO, Luís Roberto; MELLO, Patrícia Perrone Campos. Como salvar a Amazônia: por que a floresta de pé $\square$ vale mais do que derrubada. Revista de Direito da Cidade, v. 12, n. 2, 2020, p. 346.

92 Lei n. 11.952/2009 (governo Lula); Lei n. 13.465/2017 (governo Temer); e Medida Provisória 910/2019 (governo Bolsonaro). A última perdeu sua validade sem que fosse apreciada, tendo coincidido com o período da pandemia da COVID-19.

93 Daí a importância de que as terras indígenas estejam demarcadas e homologadas, providência que tem, contudo, encontrando resistência por parte do Poder Público desse sempre e de forma especialmente intensa perante o atual chefe do Executivo federal.

94 BARROSO, Luís Roberto; MELLO, Patrícia Perrone Campos. Como salvar a Amazônia: por que a floresta de pé vale mais do que derrubada. Revista de Direito da Cidade, v. 12, n. 2, 2020, p. 342; BRASIL. Ministério Público Federal. Mineração ilegal de ouro na Amazônia: marcos jurídicos e questões controversas. Brasília: MPF, 2020. p. 173-174. 
"coisa", acessória e instrumental aos interesses humanos. Vale ilustrar o ponto com alguns relatos de distintos Povos Indígenas, que conferem a elementos da natureza atributos de pessoa ou que trazem lendas de seres encantados e perigosos que defendem bens relevantes como a água. Curiosamente, Povos diferentes apresentam narrativas próximas. Confira-se:

\section{Lenda do Rio Amazonas (Povo Indígena da Amazônia, Brasil)}

"Muito tempo atrás, quando os animais ainda falavam, o Sol se apaixonou pela Lua e teve seu amor correspondido por ela. Eles perceberam em bem pouco tempo, entretanto, que, ao se aproximarem, um destruía o outro: o Sol derretia a Lua e a Lua apagava o Sol. Eles perceberam, assim, ser este amor impossível [...]. Foi então que eles resolveram se separar. A Lua inconformada com a separação chorou dias e noites seguidas. Suas lágrimas abundantes correram por cima da Terra [...]. Assim essas águas que eram lágrimas da Lua [...] se transformaram em nosso grandioso rio Amazonas." "95 (Grifouse)

\section{Conto do Cuidador da Água (Povo Indígena Pewenche, Chile):}

"Para a natureza a água é muito importante, aqui há gente que cuida da água, "Kühuin-Malen", mas se pode conversar com eles. Cada água tem seu cuidador. Eles têm rabo de peixe. É uma senhorita com tranças longas, até debaixo da cintura, de cabelo cor de ouro. De manhã, se penteia com pentes de ouro. Deus a deixou aí para que cuide da água.

É como a padroeira de todos os Punalka, manda neles. (Grifou-se)

O Pewenche roga para que cuide da água."’66

\section{Lenda da Iara, Mãe d’Água (Povos da Amazônia, Brasil):}

“[...] Iara, ou mais conhecida como a fabulosa Mãe d’Água [...], trata-se de uma mulher lindíssima, com a pele bastante clara, cabelos negros que pendem até a cintura, seios fartos e sempre à mostra, nua até a metade do corpo, mais precisamente da cintura para cima; daí para baixo, tem a forma e a cauda de um peixe. [...] é um ser encantado que vive nos lagos, nos rios e sobre os ramos fechados das flores de igarapés. Os índios e sertanejos são unânimes em afirmar que todo aquele que vê a tal da Iara fica imediatamente atraído por sua beleza e formosura, acaba sendo arrastado por ela, por causa de seu canto maravilhoso, para o fundo das águas turvas. Por esse motivo, tanto índios como sertanejos não facilitam e tomam muito cuidado, afastando-se dos lagos e rios, como também nunca passam próximo aos igarapés ao cair da tarde. Eles possuem verdadeiro pavor dos encantamentos da Iara [...]." ${ }^{.97}$ (Grifou-se)

Por fim, no que se refere a mecanismos de participação e diálogo, como já mencionado, a Constituição prevê que os Povos Indígenas devem ser ouvidos sobre o aproveitamento dos recursos hídricos e a pesquisa e a lavra das riquezas minerais em suas terras. Do mesmo modo, a Convenção 169 da OIT, incorporada ao direito brasileiro com status supralegal (art. $5^{\circ}, \$ 2^{\circ}, \mathrm{CF}$ ), assegura aos Povos Indígenas o direito à consulta quanto a medidas administrativas e legislativas suscetíveis de afetá-los diretamente (artigo $6^{\circ}$, 1, "a"), bem como amplo direito de participação no que respeita às ações voltadas à sua proteção (artigo $2^{\circ}$ ), às políticas públicas que lhes sejam concernentes (artigo $6^{\circ}, 1$, "b”), à formulação de planos de desenvolvimento que possam afetá-los (artigo $\left.7^{\circ}, 1\right)$, à melhoria dos serviços de saúde que lhes são destinados (artigo $7^{\circ}, 2$ ). Tais direitos à consulta e à participação permitem que esses Povos vocalizem suas apreensões quanto a atividades e empreendimentos que possam gerar danos ao habitat em que vivem e, nessa medida, favorecem a incorporação da perspectiva ambiental em tais processos decisórios.

Entretanto, merece registro o fato de que, a despeito das múltiplas normas já referenciadas, parte dos

\footnotetext{
5 GÓMEZ PLATERO, Ana María; EHRICHS, Victoria Palma. Leyendas de la Amazonia Brasileña. Brasília: Consejería de Educación de la Embajada de España, Secretaría General Técnica, 2011. p. 13.

96 Asociación Markan Kura de Ikalma. Conocimiento Pewenche: tradiciones y prácticas sobre cuidado y protección del medio ambiente. Lonkimay: Fundación Instituto Indígena, 2004. p. 22.

${ }_{97}$ GÓMEZ PLATERO, Ana María; EHRICHS, Victoria Palma. Leyendas de la Amazonia Brasileña. Brasília: Consejería de Educación de la Embajada de España, Secretaría General Técnica, 2011. p. 45.
} 
direitos dos Povos Indígenas sofre de uma baixíssima implementação na prática. Esse déficit de implementação é fruto da sua própria vulnerabilidade, estigmatização e sub-representação, bem como da preponderância de interesses de grupos que dominam a cena política e econômica ${ }^{98}$. Merece reiteração, ainda, o já mencionado processo de precarização por que têm passado as instituições voltadas à sua proteção, possivelmente produto das mesmas causas, e que prejudicam enormemente a concretização dos direitos de tais Povos e sua contribuição para a proteção da Natureza ${ }^{99}$.

\subsection{A contribuiç̧ão da Natureza para a proteção dos Povos Indígenas}

A proteção à Natureza, a seu turno, também contribui para a preservação dos direitos dos Povos Indígenas, sob três perspectivas: (i) reforça a tutela de seu habitat; (ii) permite a atração dos princípios da precaução e da prevenção para proteção de tais Povos; (iii) impõe a inclusão da questão indígena nos estudos de impacto ambiental. No que respeita à tutela de seu habitat, como já exposto, há uma profunda relação entre a identidade cultural dos Povos Indígenas, o território que ocupam e o meio ambiente. Tais povos extraem de tal território e de seu ambiente alimentos, plantas medicinais e interagem, cultural e espiritualmente com ele, atribuindo-lhe propriedades e valores transcendentes. A preservação da Natureza protege, nessa medida, a sua reprodução física e cultural, seus modos de fazer, criar e viver ${ }^{100}$.

Quanto à atraşão dos princípios da precaução e da prevenção para a tutela de tais Povos, como já exposto, qualquer prejuízo à Natureza pode colocar em risco a sua vida, a sua saúde, a sua cultura e os referentes cosmogônicos que lhe atribuem sentido. Por isso e dada e relação de interdependência entre Povos Indígenas e meio ambiente, também a proteção indígena atrai a incidência de tais princípios. Já no que se refere à inclusão da questão indígena nos estudos de impacto ambiental, vale assinalar que os indígenas são vidas humanas a serem consideradas no que respeita a tais impactos, bem como são responsáveis pela conformação de um meio ambiente cultural que integra o patrimônio cultural brasileiro e que se sujeita igualmente à proteção. Nessa medida, eventuais impactos adversos a tais Povos, a seu habitat e à sua projeção cultural devem, necessariamente, ser considerados em tais estudos, procedimento que, de igual modo, reforça a sua proteção e atrai a sua participação nos processos de licenciamento.

Merece, ainda, registro ressalva semelhante àquela efetuada quanto à implementação dos direitos dos Povos Indígenas. Temos no Brasil uma proteção constitucional generosa à Natureza. Somos parte de inúmeros tratados internacionais, inclusive e em especial daqueles que tratam da mitigação das mudanças climáticas. Nos comprometemos com uma meta ousadíssima de redução da emissão de gases de efeito estufa e, portanto, com a contenção do desmatamento e da alteração da cobertura e dos usos do solo.

Apresentamos, ainda, um conjunto considerável de normas infraconstitucionais que regulam as mais diversas obrigações ambientais, bem como o licenciamento ambiental de empreendimentos, atividades e serviços. A despeito disso, a implementação de tais normas e compromissos, na prática, pode se ver frustrada pela contraposição de interesses políticos e econômicos. Além disso, e tal como ocorre com os Povos Indígenas, as instituições de tutela do meio ambiente vêm sofrendo um processo de precarização e desmon-

\footnotetext{
98 MELLO, Patrícia Perrone Campos; FAUNDES, Juan Jorge. Constitucionalismo em rede: o direito à identidade cultural dos povos indígenas como filtro hermenêutico para tutela da tradicionalidade da ocupação da terra. In: ROSSITO, F. D. et al. Quilombolas e outros povos tradicionais. Curitiba: CEPEDIS, 2020. p. 317-339.

99 AMORIM, Fabrício. Povos indígenas isolados no Brasil e a política indigenista desenvolvida para efetivação de seus direitos: avanços, caminhos e ameaças. Revista Brasileira de Linguística Antropológica, v. 8, n. 2, p. 19-39, 2016; INSTITUTO SOCIOAMBIENTAL. Servidores denunciam precarização de frentes de proteção a indios isolados. nov. 2019. Disponível em: https://www.socioambiental.org/ $\mathrm{pt-br/blog/blog-do-monitoramento/servidores-denunciam-precarizacao-de-frentes-de-protecao-a-indios-isolados} \mathrm{Acesso} \mathrm{em:} 30$ set. 2020.

100 FAUNDES, Juan Jorge; CARMONA, Cristobal; SILVA, Pedro Pablo. La Corte Interamericana de Derechos Humanos. Hermeneutica del derecho al medio ambiente sano, a la identidad cultural y a la consulta, a la luz de la sentencia "Lhaka Honhat (nuestra tierra) vs. Argentina (2020)". Revista Brasileira de Políticas Públicas, v. 11, n. 2, 2020.
} 
te, com a extinção de órgãos, a insuficiência de servidores e a redução de orçamentos ${ }^{101}$.

\section{Giro Hermenêutico: da dignidade humana à dignidade da Natureza, do antropocentrismo ao ecocentrismo}

O princípio da dignidade da pessoa humana é uma ideia consolidada no Direito Internacional dos direitos humanos, no direito comparado e no direito constitucional brasileiro. A Constituição de 1988 reconhece a dignidade da pessoa humana como fundamento do Estado Democrático de Direito (art. $\left.1^{\circ}, \mathrm{III}, \mathrm{CF}\right)^{102}$. $\mathrm{Na}$ doutrina constitucional brasileira, o princípio é compreendido como núcleo essencial e base (ainda que não exclusiva) de que emanam, em maior ou menor grau, os direitos fundamentais ${ }^{103}$. Trata-se de norma que desempenha múltiplas funções. É um princípio hermenêutico que orienta a interpretação das normas constitucionais e a releitura das normas infraconstitucionais. Constitui um instrumento de integração a partir do qual direitos não afirmados expressamente no texto constitucional podem ser reconhecidos. É um parâmetro para a ponderação entre direitos constitucionais em tensão, conferindo peso reforçado aos direitos que mais se aproximem da ideia de dignidade ${ }^{104}$.

A dignidade humana associa-se à ideia de superioridade e de valor intrínseco da pessoa bumana, ao reconhecimento de que cada vida humana é um valor e fim em si mesmo e, por isso, não pode ser tratada apenas como instrumento para a consecução de outros fins, mas, ao contrário, deve ser tratada com igual consideração e respeito. Trata-se de uma ideia com raízes bastante remotas, justificada com base em distintos fundamentos, entre os quais merecem relevo concepções religiosas sobre a criação do ser humano à imagem e semelhança de Deus e concepções seculares ${ }^{105}$.

No que se refere às últimas, a doutrina de Kant é considerada uma das mais importantes formulações sobre a dignidade humana e tem por contexto o antropocentrismo, o liberalismo e o individualismo iluminista ${ }^{106}$. De acordo com Kant, enquanto as coisas têm um preço e são substituíveis, os seres humanos têm dignidade (que corresponde justamente a seu valor intrínseco absoluto). Na visão kantiana, a dignidade tem por base a autonomia, que, por sua vez, se fundamenta na capacidade de autogoverno de cada indivíduo fundada na razãa $0^{107}$. A razão é, portanto, o elemento central para o reconhecimento de um valor superior. Essas ideias, na ocasião em que foram formuladas, eram extremamente progressistas e constituíam um elemento de afirmação da liberdade, no sentido de não ingerência do Estado em uma determinada esfera existencial do indivíduo; bem como da igualdade, com o significado de que todas as pessoas, por serem racionais, devem gozar do mesmo valor e da mesma proteção. Constituía um marco na superação do teocentrismo, do poder estatal ilimitado e da hierarquização entre pessoas ${ }^{108}$.

101 BARROSO, Luís Roberto; MELLO, Patrícia Perrone Campos. Como salvar a Amazônia: por que a floresta de pé vale mais do que derrubada. Revista de Direito da Cidade, v. 12, n. 2, p. 331-376, 2010. p. 348-350.

102 A proteção à dignidade aparece, ainda, como fundamento do planejamento familiar de livre decisão do casal (art. 226, $\left.\int 7^{\circ}, \mathrm{CF}\right)$, como direito da criança, do adolescente, do jovem (art. 227, CF) e das pessoas idosas (art. 230, CF).

103 SARLET, Ingo. A eficácia dos direitos fundamentais: uma teoria geral dos direitos fundamentais na perspectiva constitucional. 12. ed. Porto Alegre: Livraria do Advogado, 2015. p. 73-74.

104 SARMENTO, Daniel. Dignidade da pessoa humana: conteúdo, trajetórias e metodologia. 2. ed. Belo Horizonte: Fórum, 2016. p. 326.

105 SARMENTO, Daniel. Dignidade da pessoa humana: conteúdo, trajetórias e metodologia. 2. ed. Belo Horizonte: Forum, 2016, pp. 27-32. 106 BOBBIO, Norberto. Direito e Estado no pensamento de Emmanuel Kant. São Paulo: Mandarim, 2000. p. 17-20.

107 KANT, Immanuel. Groundwork of the Metaphysics of Morals. Cambridge: Cambridge University Press, 1997; BARROSO, Luís Roberto. La dignidad de la persona humana en el derecho constitucional contemporáneo. Bogotá: Universidad Externado de Colombia, 2014. p. 123-129. SARMENTO, Daniel. Dignidade da pessoa humana: conteúdo, trajetórias e metodologia. 2. ed. Belo Horizonte: Fórum, 2016. p. 106-109; BOBBIO, Norberto. Direito e Estado no pensamento de Emmanuel Kant. São Paulo: Mandarim, 2000. p. 86-107.

108 Outros autores relevantes desenvolveram ideias similares um pouco mais tarde. Nesse sentido, Rawls defendeu que cada pessoa possui uma "inviolabilidade intrínseca", que nem o bem-estar da sociedade pode sobrepujar RAWLS, John. A theory of justice. Cambridge: Harvard University Press, 1971. p. 3-4). Dworkin desenvolveu a ideia de "direitos como trunfos" contra a maioria. 
No entanto, algumas consequências possíveis de tal doutrina merecem destaque. Entre elas: a afirmação de que o ser que supostamente não é capaz de exercer razão e, portanto, autonomia no sentido kantiano, é desprovido de dignidade. Nessas condições, esse ser é uma "coisa", que tem um "preço de mercado", é substituível, não constitui um fim em si mesmo, podendo ser instrumentalizado. Trata-se de uma abordagem que lança luzes importantes sobre como a Natureza e os demais seres vivos foram tratados até o momento presente. Justamente como coisas precificáveis e substituíveis, desprovidas de dignidade, destinadas a servir aos interesses e às necessidades humanas. Assim, esse paradigma, profundamente progressista como já observado, paradoxalmente, poderia justificar a exploração ilimitada da Natureza como coisa precificável e substituível e a incompreensão da interdependência entre todas as formas de vida ${ }^{109}$.

Nesse ponto, e sem deixar de reconhecer a relevância da afirmação da dignidade da pessoa humana, é importante fazer o registro de que a razão como critério distintivo da superioridade entre os seres humanos e os demais seres vivos pode constituir um critério bastante arbitrário, sobretudo quando achados da psicologia e da neurociência demonstram que grande parte dos nossos comportamentos e escolhas não se funda, propriamente, na razão, mas em preconcepções e mecanismos inconscientes, e que, em tais circunstâncias, a razão serve, de modo geral, mais como um elemento de justificação do que efetivamente como um elemento de decisão autônoma ${ }^{110}$.

Além disso, trata-se de paradigma que não é capaz de oferecer resposta ou tratamento aos dilemas que a crise climática nos apresenta ${ }^{111}$. A crise climática demonstra que a proteção da Natureza e a existência de um meio ambiente saudável constituem precondição para o exercício de todos os direitos fundamentais. Sem Natureza e meio ambiente equilibrado, não há vida, saúde, acesso à água potável, ao alimento, à moradia, tampouco se pode falar em uma vida digna para os seres humanos. Assim, sem prejuízo de seguirmos defendendo a dignidade da pessoa humana, em suas vertentes de liberdade e de igualdade entre as pessoas, parece ao menos prudente e recomendável que questionemos a afirmação da superioridade humana com base no exercício da razão e a rejeição do reconhecimento da dignidade da Natureza.

Esse parece ser o caminho que a crise climática nos aponta. Caso tenhamos êxito em seu enfrentamento, é possível que, no futuro, olhemos para os dilemas atuais - centralidade humana em oposição à centralidade da Natureza e não reconhecimento da dignidade desta última - com a mesma estranheza com que olhamos, hoje, para a ideia de que a Terra é o centro do Universo ou para a justificação da escravidão e sujeição de negros africanos e de indígenas com base no argumento de que não dispunham de alma. Trata-se, afinal, de paradigmas científicos e morais que demonstram como a racionalidade humana é falível e como a moral é cultural e contingente.

Nesse sentido, a hermenêutica intercultural demonstra que a compreensão de mundo da cultura atualmente dominante (e dos seus julgadores) não é universal. É, apenas, uma entre as muitas compreensões que devem ser tidas em conta. Na cosmovisão indígena, a Natureza tem um valor e uma centralidade que preci-

DWORKIN, Ronald. Rights as trumps. In: WALDRON, Jeremy (ed.). Theories of rights. New York: Oxford University Press, 1984. p. 153-167. Nino afirmou o "princípio da inviolabilidade da pessoa", que impede sacrifícios involuntários em favor da coletividade NINO, Carlos Santiago. Ética y derechos humanos. 2 ed. Buenos Aires: Astrea, 1989.

109 GUDYNAS, Eduardo. La senda biocéntrica: valores intrínsecos, derechos de la naturaleza y justicia ecológica. Tabula Rasa, n. 13, p. 45-71, jul./dez. 2010. p. 48-49.

110 TVERSKY, Amos; KAHNEMAN, Daniel. The framing of decisions and the psychology of choice. In: ELSTER, Jon. Rational choice. Nova Iorque: New York University, 1986. p. 123-141; ELSTER, Jon. Explaining social behavior: more nuts and bolts for the social sciences. Nova Iorque: New York University, 1986. Na literatura nacional: MELLO, Patrícia Perrone. Nos bastidores do STF. Rio de Janeiro: Forense-Gen, 2018. p. 152-155; NOJIRI, Sergio. O Direito Irracional: emoção e intuição no processo de tomada de decisão judicial. Tese (Livre Docência) - Faculdade de Direito de Ribeirão Preto, Universidade de São Paulo, Ribeirão Preto, 2019; HORTA, Ricardo Lins. Por que existem vieses cognitivos na tomada da decisão judicial? a contribuição da psicologia e das neurociências para o debate jurídico. Revista Brasileira de Politicas Públicas, v. 9, n. 3, p. 85-122, dez. 2019.

111 Na doutrina de Thomas Khun, a revolução científica é uma consequência de uma crise de paradigmas, que ocorre quando um antigo paradigma não é mais capaz de oferecer respostas satisfatórias ou coerentes para novos problemas. Segundo Khun, a crise gera a substituição do antigo paradigma por um novo paradigma, que passa a orientar novas soluções. KHUN, Thomas. Estrutura das revoluções científicas. São Paulo: Perspectiva, 2017. 
sam ser consideradas. A hermenêutica biocêntrica e/ou ecocêntrica, de forma similar, reconhece a dignidade da vida (humana ou não humana) ou da Natureza (incluídos os elementos sem vida), bem como seu valor como um fim em si mesmo.

Essas considerações nos levam a sugerir que, sem desconsiderar o valor da dignidade humana e sua inestimável importância para a consolidação de uma cultura de respeito aos direitos fundamentais, é possível que estejamos vivendo um momento de trânsito, no direito constitucional, para o reconhecimento também do ecocentrismo como núcleo essencial e base dos direitos fundamentais, à luz do qual se deve buscar a releitura de todo o ordenamento jurídico, o reconhecimento de novos direitos e a redefinição de pesos diferenciados prima facie na ponderação entre bens constitucionais em tensão. Esse é o novo paradigma que a crise climática parece "sugerir". Paradigma que, como os novos paradigmas em geral, enfrenta resistências tão potentes quanto aquelas enfrentadas pela afirmação do heliocentrismo e pela superação da escravidão. Trata-se, contudo, no limite, de uma questão de sobrevivência. Literalmente.

\section{Considerações finais}

Em resposta às questões que o presente trabalho se propôs a enfrentar, os Povos Indígenas têm contribuição relevante a oferecer à proteção da Natureza. A presença de tais Povos nas florestas, sua vigilância e o regime jurídico que lhes é aplicável geralmente garantem uma maior efetividade da preservação ambiental. As práticas, costumes e tradições de suas comunidades promovem, de modo geral, uma ressignificação do valor da Natureza, que reforça seu resguardo. O regime de proteção a tais Povos prevê, ainda, mecanismos de participação e de diálogo que favorecem a tutela da Natureza (embora não se deva desconsiderar que também podem gerar riscos para ela, por exemplo, no que se refere às normas que preveem a participação das comunidades indígenas nos benefícios de projetos extrativos). Além disso, a hermenêutica intercultural ensina que o juiz, ao apreciar demandas indígenas, deve considerar o valor e o significado que a sua cultura dos últimos atribui a comportamentos e bens. Na cultura indígena, como regra, a Natureza tem valor intrínseco, central e transcendente.

Do mesmo modo, a Natureza e o regime jurídico que lhe é aplicável desempenham um papel importante para a proteção de tais Povos. A preservação da Natureza reforça a tutela de seu habitat e de sua reprodução física e cultural, dada a profunda interdependência entre ambos. Tal interdependência justifica a aplicação dos princípios da precaução e da prevenção, de viés ambiental e sanitário, à tutela dos Povos Indígenas. Por razões idênticas, impõe-se, ainda, a inclusão da questão indígena nos estudos de impacto ambiental de empreendimentos que possam gerar danos ao meio ambiente e/ou a tais povos, inclusive em uma perspectiva cultural. A hermenêutica ecocêntrica, a seu turno, reconhece à Natureza um valor intrínseco, como bem em si e como conjunto de elementos e processos essenciais à preservação do Planeta e da vida dos seres que o habitam. Nessa medida, é convergente com a cosmovisão indígena.

No que respeita a um possível "giro hermenêutico" em matéria de interpretação constitucional, a relação de interdependência entre a Natureza, a vida de todo e qualquer ser e o exercício de direitos fundamentais; os aportes da hermenêutica intercultural; a contribuição da hermenêutica ecocêntrica; e, por fim, a gravidade da crise climática que enfrentamos, bem como das suas consequências, demonstram que a forma pela qual nos relacionamos com a Natureza precisa ser alterada. Os paradigmas econômicos, sociais, jurídicos e éticos que nos serviram de base não são mais capazes de oferecer respostas à questão mais premente que temos a enfrentar: a contenção e a reversão da destruição ambiental que pode comprometer a viabilidade da vida na Terra. Integramos a Natureza, somos incapazes de controlá-la e profundamente dependentes do seu equilíbrio, como condição para o exercício de todos os direitos que tanto valorizamos. Nesse contexto, não somos superiores ou mais dignos de tutela que os demais seres porque todos dependemos do todo. 
Tais constatações tendem a nos conduzir ao reconhecimento da centralidade da Natureza e do equilíbrio ambiental como direito-matriz e como base de que depende o exercício de todos os demais direitos, inclusive dos direitos humanos. Elas permitem que se reconheça que o direito ao meio ambiente saudável tem relevância ao menos paralela à dignidade humana. Esse reconhecimento implica, do ponto de vista hermenêutico, ressignificar todo o ordenamento jurídico à luz desse valor. Trata-se, portanto, de entendimento com aptidão para produzir grandes mudanças na compreensão do Direito como um todo. Mudanças de paradigma provocam enormes resistências e importantes rupturas. Não são rápidas, nem fáceis. Entretanto, apresentam grandes oportunidades: de uma vida mais equilibrada, mais solidária, menos arrogante. Nesse sentido, temos muito a aprender com a Natureza.

\section{Referências}

ABRAMOVAY, Ricardo. Amazônia: por uma economia de conhecimento da natureza. São Paulo: Elefante, 2019.

Acosta, A. Extractivismo y neoextractivismo: dos caras de la misma maldición. In: LANG, M.; MOKRANI, D. Más allá del desarrollo. Quito: Fundación Rosa Luxemburgo/Abya Yala, 2012. p. 83-118.

Aguilar Castro, Vladimir. Extractivismo, derechos humanos y desafección política en Venezuela. In: SORIANO DIAZ, Ramón Luis; SANCHES RUBIO, David; Suárez Villegas, Juan Carlos (eds.). Las fronteras de los derechos humanos: problemas, discusión y Soluciones. Madrid: Dikinson, 2020.

Alayza, A.; Gudynas, E. Transiciones y alternativas al extractivismo en la región andina. Lima: Centro Peruano de Estudios Sociales, 2012.

Altvater, Elmar et al. Las limitaciones de la globalización: economía, ecología y política de la globalización. Madrid: Siglo XXI Ediciones, 2002.

Altvater, Elmar. ¿Existe un marxismo ecológico? In: Borón, A.; Amadeo, J. González, S. (ed.). La teoría marxista hoy, problemas y perspectivas. Buenos Aires: CLACSO, 2006. p. 341-363.

AMORIM, Fabrício. Povos indígenas isolados no Brasil e a política indigenista desenvolvida para efetivação de seus direitos: avanços, caminhos e ameaças. Revista Brasileira de Linguística Antropológica, v. 8, n. 2, p. 19-39, 2016.

ANAYA, James. Principios internacionales aplicables a la consulta en relación con la reforma constitucional en materia de derechos de los pueblos indígenas en Chile. Disponível em: https:/ /www.ohchr.org/Documents/Issues/IPeoples/ SR/InformeConsultaChile.pdf Acesso em: 26 set. 2020.

ANTKOWIAK, Thomas. Rights, ressources and rhetoric: indigenous peoples and te Inter-American Court. American Court, v. 35, n. 113, 2013. Disponível em: https://scholarship.law.upenn.edu/jil/vol35/iss1/3 Acesso em: 30 set. 2020.

ANTONIAZZI, Mariela Morales. O estado aberto: objetivo do Ius Constitucionale Commune em Direitos Humanos. In: BOGDANDY, Armin von; ANTONIAZZI, Mariela MORALES; PIOVESAN, Flávia (coord.). Ius Constitucionale Commune na América Latina: marco conceptual. Curitiba: Juruá, 2016. v. 1.

Asociación Markan Kura de Ikalma. Conocimiento Pewenche: tradiciones y prácticas sobre cuidado y protección del medio ambiente. Lonkimay: Fundación Instituto Indígena, 2004.

BARAGWANATH, Kathryn; BAYL, Ella. Collective property rights reduce deforestation in the Brazilian Amazon. PNAS Latest Articles, jul. 2020. Disponível em: https://www.amazoniasocioambiental.org/wp-content/uploads/2020/08/10.1073@pnas.1917874117.pdf. Acesso em 30 set. 2020.

BARROSO, Luís Roberto. La dignidad de la persona bumana en el derecho constitucional contemporáneo. Bogotá: Universidad Externado de Colombia, 2014. 
BARROSO, Luís Roberto; MELLO, Patrícia Perrone Campos. Como salvar a Amazônia: por que a floresta de pé vale mais do que derrubada. Revista de Direito da Cidade, v. 12, n. 2, p. 331-376, 2010.

BELTRÃO, Jane Felipe et al. Derechos humanos de los grupos vulnerables: guía de prácticas. Barcelona: DHES, Red de Derechos Humanos y Educación Superior, 2014.

BERMÚDEZ, Jorge. Fundamentos del Derecho Ambiental. Santiago: Ediciones Universitarias de Valparaíso, 2015.

BOBBIO, Norberto. Direito e Estado no pensamento de Emmanuel Kant. São Paulo: Mandarim, 2000.

BOGDANDY, Armin von. Ius Constitucionale Commune na América Latina: uma reflexão sobre um Constitucionalismo Transformador. Revista de Direito Administrativo, Rio de janeiro, v. 269, maio/ago. 2015.

BRANDÃO, Juliana Mendanha; MAHFOUD, Miguel; GIANORDOLI-NASCIMENTO, Ingrid Faria. A construção do conceito de resiliência em psicologia: discutindo as origens. Paidéia, v. 21, n. 49, 2011.

BRASIL. Ministério Público Federal. Mineração ilegal de ouro na Amazônia: marcos jurídicos e questões controversas. Brasilia: MPF, 2020.

BRASIL. Supremo Tribunal Federal. Arguição de Descumprimento de Preceito Fundamental. ADPF 709/ DF. Relator: Min. Luís Roberto Barroso, 1 de julho de 2020. Disponível em: http://portal.stf.jus.br/processos $/$ detalhe.asp?incidente $=5952986$ Acesso em: 30 set. 2020 .

CAPOBIANCO, João Paulo Ribeiro. Governança socioambiental na Amarônia brasileira na década de 2000. 2017. Tese (Doutorado) - Instituto de Energia e Ambiente, Universidade de São Paulo, São Paulo, 2017.

CARMONA, Cristóbal. Consentimiento Libre Previo e Informado en el contexto de proyectos extractivos en territorio indígena ¿Regla general y Derecho Consuetudinario Internacional? Revista Brasileira de Políticas Públicas, v. 9, n. 3, p. 372-399, 2019.

CARMONA, Cristóbal. Tomando los derechos colectivos en serio: el derecho a consulta previa del convenio 169 de la OIT y las instituciones representativas de los Pueblos indígenas. Ius et Praxis, ano 19, n. 2, p. 301-334, 2013.

CAVALLAZZI, Vanessa Wendhausen; MELLO, Patrícia Perrone Campos; SOARES, Raony. Educação superior intercultural, reconhecimento e redistribuição: o duro caminho dos povos indígenas no Equador. Brazilian Journal of International Law, v. 15, n. 1, p.179-198, 2018.

CEBALLOS, Gerardo et al. Accelerated modern human-induced species losses: Entering the sixth mass extinction. Science Advances, p. 1-5, 2015.

COLÓN-RÍOS, Joel. Guardianes de la Naturaleza. In: ESTUPIÑAN, Liliana et al. (ed.). La naturaleza como sujeto de derechos en el constitucionalismo democrático. Bogotá: Universidad Libre, 2019. p. 205-226.

CORTE INTERAMERICANA DE DIREITOS HUMANOS. “Caso Bámaca Velásquez, vs. Guatemala” (Fundo). Sentença de 25 de novembro de 2000.

CORTE INTERAMERICANA DE DIREITOS HUMANOS. "Caso Comunidad Garifuna de Punta Piedra y sus miembros vs. Honduras" (Fundo, Reparações e Custas). Série 305. Sentença de 8 de outubro de 2015.

CORTE INTERAMERICANA DE DIREITOS HUMANOS. "Caso Comunidad Indígena Moiwana vs. Surinam” (Exceções preliminares, fundo, reparações e custas). Sentença de 15 de junho de 2005.

CORTE INTERAMERICANA DE DIREITOS HUMANOS. "Caso Comunidad Indígena Yakye Axa vs. Paraguay” (Fundo, reparações e custas). Sentença de 17 de junho de 2005.

CORTE INTERAMERICANA DE DIREITOS HUMANOS. "Caso Comunidad Indígena Yakye Axa” vs. Paraguay (Interpretação da Sentença de Fundo, Reparações e Custas). Sentença de 6 de fevereiro de 2006. 
CORTE INTERAMERICANA DE DIREITOS HUMANOS. "Caso comunidades indígenas miembros de la asociación Lhaka Honhat (nuestra tierra) vs. Argentina" (Fundo, Reparações e Custas). Sentença de 6 de fevereiro de 2020 .

CORTE INTERAMERICANA DE DIREITOS HUMANOS. "Caso de la Comunidad Indígena Sawhoyamaxa vs. Paraguay” (Fundo, Reparações e Custas). Sentença de 29 de março de 2006.

CORTE INTERAMERICANA DE DIREITOS HUMANOS. "Caso del Pueblo Indígena Kichwa de Sarayaku vs. Ecuador" (Fundo e Reparações). Sentença de 27 junho de 2012.

CORTE INTERAMERICANA DE DIREITOS HUMANOS. "Caso del Pueblo Saramaka vs. Surinam” (Exceções Preliminares, Fundo, Reparações e Custas). Sentença de 28 novembro 2007.

CORTE INTERAMERICANA DE DIREITOS HUMANOS. "Caso Masacre Plan de Sánchez vs. Guatemala" (Reparações). Sentença de 19 de novembro de 2004.

CORTE INTERAMERICANA DE DIREITOS HUMANOS. "Caso Norín Catrimán y otros (dirigentes, miembros y activista del pueblo indígena mapuche) vs. Chile" (Fundo, Reparações e Custas). Sentença de 29 de maio de 2014.

CORTE INTERAMERICANA DE DIREITOS HUMANOS. "Caso Pueblo Indígena Xucuru y sus miembros vs. Brasil” (Excepções Preliminares, Fundo, Reparações e Custas). Sentença de 5 de fevereiro de 2018.

CORTE INTERAMERICANA DE DIREITOS HUMANOS. "Comunidad (Sumo) Awas Tigni Vs. Nicaragua” (Fundo, Reparações e Custas). Sentença de 31 agosto 2001.

CORTE INTERAMERICANA DE DIREITOS HUMANOS. "Comunidad indígena Xákmok Kásek vs. Paraguay” (Fundo, Reparações e Custas). Sentença de 24 de agosto de 2010.

CORTE INTERAMERICANA DE DIREITOS HUMANOS. Opinião Consultiva OC-23/17, "Solicitada por la República de Colombia sobre medio ambiente y derechos humanos", de 15 de novembro de 2017.

DEL CARPIO, Columba. Pluralismo Jurídico, derecho bumano a la identidad cultural y globalización. Navarra: Editorial Aranzadi SA, 2014.

DESMATAMENTO na Amazônia aumenta 85,3\% em 2019, aponta INPE. Veja, 14 jan. 2020. Disponível em: https://veja.abril.com.br/brasil/desmatamento-na-amazonia-aumenta-853-em-2019-aponta-inpe/ Acesso em: 26 set. 2020.

DWORKIN, Ronald. Rights as trumps. In: WALDRON, Jeremy (ed.). Theories of rights. New York: Oxford University Press, 1984. p. 153-167.

ELSTER, Jon. Explaining social behavior more nuts and bolts for the social sciences. Nova Iorque: New York University, 1986.

ENGLE, Karen. The elusive promise of indigenous development: rights, culture, strategy. Durham: Duke University Press, 2010. [ebook]

FAUNDES PEÑAFIEL, Juan Jorge; RAMÍREZ, Silvina. Introducción. El derecho a la identidad cultural, horizontes plurales latinoamericanos. In: FAUNDES, Juan Jorge; RAMÍREZ, Silvina (org.). Derecho fundamental a la identidad cultural, abordajes plurales desde América Latina. Santiago: RIL, Universidad Autónoma de Chile, 2020.

FAUNDES, Juan Jorge. Consulta indígena y centrales de generación hidroeléctrica de menos de 3MW: desregulación riesgosa, a la luz del derecho fundamental a la identidad cultural de los pueblos indígenas. In: BOZZO, Sebastián; REMESEIRO, Rebeca; ESIS, Ivette (ed.). Memorias III Congreso Internacional de Regulación y Consumo. Santiago: RIL, Universidad Autónoma de Chile, 2020. p. 359-398. 
FAUNDES, Juan Jorge. El derecho fundamental a la identidad cultural de los pueblos indígenas: un derecho-matriz y filtro hermenéutico para las constituciones de América Latina: la justificación. Revista Brasileira de Políticas Públicas, v. 9, n. 2, ago. 2019.

FAUNDES, Juan Jorge. El derecho fundamental a la identidad cultural de los pueblos indígenas, configuración conforme el derecho internacional y perspectivas de su recepción en Chile. Ius et Praxis, v. 26, n. 1, p. 77-100, 2020.

FAUNDES, Juan Jorge; CARMONA, Cristobal; SILVA, Pedro Pablo. La Corte Interamericana de Derechos Humanos. Hermeneutica del derecho al medio ambiente sano, a la identidad cultural y a la consulta, a la luz de la sentencia "Lhaka Honhat (nuestra tierra) vs. Argentina (2020)". Revista Brasileira de Políticas Públicas, v. 11, n. 2, 2020.

FERNANDES, Patrícia Vieira dos Santos. A importância dos princípios da precaução e da prevenção na busca do desenvolvimento sustentável. L\&C - Revista de Administração Pública e Política, n. 156, jun. 2011.

FERREIRA, Fabíola; BOMFIM, Zulmira Áurea Cruz. Sustentabilidade Ambiental: visão antropocêntrica ou biocêntrica? AmbientalMENTEsustentable, v. 1, n. 9-10, 2010.

GÓMEZ PLATERO, Ana María; EHRICHS, Victoria Palma. Leyendas de la Amazonia Brasileña. Brasília: Consejería de Educación de la Embajada de España, Secretaría General Técnica, 2011.

GONÇALVES, Daniel Diniz; TÁRREGA, Maria Cristina Vidotte Blanco. Giro egocêntrico: do Direito Ambiental ao Direito Ecológico. Revista Direito Ambiental e Sociedade, v. 8, n. 1, p. 138-157, 2018.

GUDYNAS, Eduardo. La senda biocéntrica: valores intrínsecos, derechos de la naturaleza y justicia ecológica. Tabula Rasa, n. 13, p. 45-71, jul./dez. 2010.

HARVEY, David. El nuevo imperialismo. Madrid: AKAL, 2004.

HORTA, Ricardo Lins. Por que existem vieses cognitivos na tomada da decisão judicial? a contribuição da psicologia e das neurociências para o debate jurídico. Revista Brasileira de Políticas Públicas, v. 9, n. 3, p. 85-122, dez. 2019.

HUMAN RIGHTS WATCH. Máfias do Ipê. Nova York: HRW, 2019. Disponível em: https://www.hrw.org/ pt/report/2019/09/17/333886 Acesso em: 9 fev. 2020.

INSTITUTO BRASILEIRO DE GEOGRAFIA E ESTATÍSTICA. O Brasil Indígena. Os indígenas no Censo Demográfico de 2010. Disponível em: https://indigenas.ibge.gov.br/images/pdf/indigenas/folder_indigenas_web.pdf. Acesso em: 29 set. 2020.

INSTITUTO DE PESQUISA ECONÔMICA APLICADA. O que é? Amazônia Legal. Disponível em: https://www.ipea.gov.br/desafios/index.php?option=com_content\&id=2154:catid=28\&Itemid. Acesso em: 29 set. 2020.

Instituto Socioambiental. Invasores produzem maior desmatamento em Terras Indígenas em 11 anos. 2019. Disponível em: https://www.socioambiental.org/pt-br/noticiassocioambientais/invasores-produzem-maior-desmatamento-em-terras-indigenas-em-11-anos Acesso em: 10 maio 2020.

Instituto Socioambiental. Novo arco do desmatamento: fronteira avança em 2019 na Amazônia. 2019. Disponível em: https://www.socioambiental.org/pt-br/noticias-socioambientais/novoarco-do-desmatamento-fronteira-de-destruicao-avanca-em-2019-na-amazonia Acesso em: 3 mar.2020.

INSTITUTO SOCIOAMBIENTAL. Servidores denunciam precarização de frentes de proteção a indios isolados. nov. 2019. Disponível em: https://www.socioambiental.org/pt-br/blog/blog-do-monitoramento/servidores-denunciam-precarizacao-de-frentes-de-protecao-a-indios-isolados Acesso em: 30 set. 2020. 
KALUNGA, Bernardo. Desmatamento na Amazônia é ideológico, diz economista Ricardo Abramovay. Uol, 2020. Disponível em: https://tab.uol.com.br/noticias/redacao/2020/01/02/desmatamento-na-amazonia-e-ideologicodiz-economista-ricardo-abramovay.htm Acesso em: 9 fev. 2020.

KANT, Immanuel. Groundwork of the Metaphysics of Morals. Cambridge: Cambridge University Press, 1997.

KHUN, Thomas. Estrutura das revoluções científicas. São Paulo: Perspectiva, 2017.

LOVEJOY, Thomas E.; NOBRE, Carlos. Amazon Tipping Point. Science Advances, 2018. Disponível em: http://advances.sciencemag.org/content/4/2/eaat2340 Acesso em: 10 maio 2020.

MARIÑO, Fernando. Introducción: aproximación a la noción de persona y grupo vulnerable en el derecho europeo. In: MARINO MENÉNDEZ, Fernando; FERNÁNDEZ LIESA, C. (org.). La protección de las personas y grupos vulnerables em el derecho europeo. Madrid: Universidad Carlos III de Madrid, 2001.

MARTÍNEZ YÁNEZ, Esperanza; ACOSTA, Alberto. La Naturaleza entre la cultura, la biología y el derecho. Polis, Revista Latinoamericana, v. 13, n. 38, p. 623-627, 2014.

MELLO, Patricia Perrone Campos. Proteção à vulnerabilidade na jurisprudência do Supremo Tribunal Federal do Brasil: a defesa da população LGBTI+. Revista da AGU, Brasília, v. 19, n. 1, p. 17-43, jan./mar. 2020.

MELLO, Patrícia Perrone Campos; FAUNDES, Juan Jorge. Constitucionalismo em rede: o direito à identidade cultural dos povos indígenas como filtro hermenêutico para tutela da tradicionalidade da ocupação da terra. In: ROSSITO, F. D. et al. Quilombolas e outros povos tradicionais. Curitiba: CEPEDIS, 2020. p. 317-339.

MELLO, Patrícia Perrone. Nos bastidores do STF. Rio de Janeiro: Forense-Gen, 2018.

NAESS, Arne. The shallow and the deep, long-range ecology movement. A Summary. An Interdisciplinary Journal of Philosophy, v. 16, n. 1-4, 1973.

NINO, Carlos Santiago. Ética y derechos humanos. 2 ed. Buenos Aires: Astrea, 1989.

NOBRE, Carlos et al. Land-use and climate change risks in the Amazon and the need of a novel sustainable development paradigm. PNAS, v. 113, n. 39, p. 10759-10768, 2016.

NOJIRI, Sergio. O Direito Irracional: emoção e intuição no processo de tomada de decisão judicial. Tese (Livre Docência) - Faculdade de Direito de Ribeirão Preto, Universidade de São Paulo, Ribeirão Preto, 2019.

NUSSBAUM, Martha C. Beyond. Compassion and humanity: justice for nonhuman animals. In: NUSSBAUM, Martha C. Frontiers of justice: disability, nationality, species membership. Cambridge: Harvard University Press, 2006. p. 324-407.

OBSERVATÓRIO DOS DIREITOS HUMANOS DOS POVOS INDÍGENAS ISOLADOS E DE RECENTE CONTATO. Povos Indígenas Isolados no Brasil: Resistência Política pela autodeterminação. 2010. Disponível em: https://povosisolados.files.wordpress.com/2020/02/informe-opi-n01v4.pdf. Acesso em: 30 set. 2020 .

OLIVARES, Alberto. Contenido y desarrollo del principio in dubio pro natura. Hacia la protección integral del medio ambiente. Ius et Praxis, v. 3, n. 24, p. 619-650, 2018.

OLIVARES, Alberto. El derecho a la identidad cultural. In: AGUILAR, Gonzalo (coord.). Nuevos derechos para una nueva Constitución. Valencia: Tirant Lo Blanch, 2019.

ORGANIZAÇÃO DAS NAÇÕES UNIDAS. Acordo de Paris. Disponível em: https://www.undp.org/content/dam/brazil/docs/ODS/undp-br-ods-ParisAgreement.pdf Acesso em: 26 set. 2020.

ORGANIZAÇÃO DAS NAÇÕES UNIDAS. Carta Mundial da Natureza. Disponível em: https://www. dh-cii.eu/0_content/investigao/files_CRDTLA/convencoes_tratados_etc/carta_mundial_da_natureza_ de_28_de_outubro_de_1982.pdf Acesso em: 26 set. 2020. 
ORGANIZAÇÃO DAS NAÇÕES UNIDAS. Convenção sobre Diversidade Biológica. Disponível em: http:// www.planalto.gov.br/ccivil_03/decreto/1998/anexos/and2519-98.pdf Acesso em: 26 set. 2020.

ORGANIZAÇÃO DAS NAÇÕES UNIDAS. Convenção-Marco das Nações Unidas sobre Mudança do Clima (CMNUCC). Disponível em: http://www.mpf.mp.br/atuacao-tematica/sci/normas-e-legislacao/tratados/convencoes-meio-ambiente/convencao-quadro-das-nacoes-unidas-sobre-mudanca-do-clima.pdf/view Acesso em: 26 set. 2020.

ORGANIZAÇÃO DAS NAÇÕES UNIDAS. Declaração de Estocolmo sobre o ambiente humano - 1972. Disponível em: http://www.direitoshumanos.usp.br/index.php/Meio-Ambiente/declaracao-de-estocolmo-sobre-o-ambiente-humano.html Acesso em: 26 set. 2020.

ORGANIZAÇÃO DAS NAÇÕES UNIDAS. Declaração de Johannesburgo sobre o Desenvolvimento Sustentável. Disponível em: https://cetesb.sp.gov.br/proclima/wp-content/uploads/sites/36/2013/12/decpol.pdf Acesso em: 26 set. 2020.

ORGANIZAÇÃO DAS NAÇÕES UNIDAS. Declaração do Rio sobre Meio Ambiente e Desenvolvimento. Disponível em: https://cetesb.sp.gov.br/proclima/wp-content/uploads/sites/36/2013/12/declaracao_rio_ ma.pdf Acesso em: 26 set. 2020.

ORGANIZAÇÃO DAS NAÇÕES UNIDAS. Protocolo de Kyoto da Convenção-Marco das Nações Unidas sobre Mudança do Clima. Disponível em: http://www.direitoshumanos.usp.br/index.php/Meio-Ambiente/protocolo-de-quioto-a-convencao-quadro-das-nacoes-unidas-sobre-mudanca-do-clima.html Acesso em: 26 set. 2020.

ORGANIZAÇÃO DAS NAÇÕES UNIDAS. Transformar nuestro mundo: la Agenda 2030 para el Desarrollo Sostenible. Disponível em: https://www.undp.org/content/dam/argentina/Publications/Agenda2030/ PNUDArgent-DossierODS.pdf Acesso em: 26 set. 2020.

PACARI, Nina. Naturaleza y territorio desde la mirada de los pueblos indígenas. In: ACOSTA, Alberto; MARTÍNEZ YÁNEZ, Esperanza. Derechos de la Naturaleza. Quito: AbyaYala, 2009. p. 31-37.

PEÑA, Mario. La revolución de los derechos bumanos ambientales y de los derechos de la naturaleza. 2018. Disponível em: https://derecho.ucr.ac.cr/Posgrado/derecho-ambiental/la-revolucion-de-los-derechos-humanos-ambientales-y-de-los-derechos-de-la-naturaleza/. Acesso em: 30 set. 2020.

PRIMEIRA mulher indígena é eleita para a Câmara dos Deputados. Exame, out. 2018. Disponível em: https://exame.com/brasil/primeira-mulher-indigena-e-eleita-para-a-camara-dos-deputados/. Acesso em: 29 set. 2020 .

RAMÍREZ, Silvina. Derechos de los pueblos indígenas y derechos de la Naturaleza: encuentros y desencuentros. Revista Argentina de Teoría Jurídica, v. 12, p. 26-41, dez. 2011.

RAWLS, John. A theory of justice. Cambridge: Harvard University Press, 1971.

REIS, José Augusto; LAMARE, Júlia de. O princípio da precaução e a intervenção judicial em processos de licenciamento ambiental de empreendimentos de energia. In: STEINDORFER, Fabriccio (coord). Direito da energia elétrica. Curitiba: Juruá, 2017. p. 191-208.

SARLET, Ingo Wolfgang; FENSTERSEIFER, Tiago. Algumas notas sobre a dimensão ecológica da dignidade da pessoa humana e sobre a dignidade da vida em geral. Revista Direito e Sociedade, v. 3, n. 1, p. 69-94, 2015.

SARLET, Ingo Wolfgang; FENSTERSEIFER, Tiago. Direito constitucional ecológico. 6. ed. São Paulo: Revista dos Tribunais, 2019.

SARLET, Ingo. A eficácia dos direitos fundamentais: uma teoria geral dos direitos fundamentais na perspectiva constitucional. 12. ed. Porto Alegre: Livraria do Advogado, 2015. 
SARMENTO, Daniel. Dignidade da pessoa bumana: conteúdo, trajetórias e metodologia. 2. ed. Belo Horizonte: Fórum, 2016.

SCHERWITZ, Débora Perilo. As visões antropocêntrica, biocêntrica e ecocêntrica do direito dos animais no Direito Ambiental. Revista Direito e Sociedade, v. 3, n. 1, 2015.

SCHMIDT, Cíntia. Princípios de direito ambiental. Interesse Público, ano 13, n. 69, p. 187-207, 2011.

SEOANE, José; TADEI, Emilio; ALGRANATI, Clara. Movimientos sociales y bienes comunes de la naturaleza: características, significación y proyección de la conflictividad sociopolítica en América Latina. Buenos Aires, 2011. Disponível em: https://cdsa.aacademica.org/000-034/662.pdf Acesso em: 30 set. 2020.

SEOANE, José; TADEI, Emilio; ALGRANATI, Clara. Recolonización, bienes comunes de la naturaleza y alternativas desde los pueblos. Buenos Aires: GEAL, 2010.

SINGER, Peter. Animal liberation: new ethics for our treatment of animals, New York: Random House, 1975.

SOUZA, Pablo Ronaldo Gadea de. A terra como elemento nevrálgico da identidade indígena: a violação dos direitos coletivos territoriais dos povos indígenas e seu tratamento no âmbito do sistema interamericano de proteção aos direitos humanos. Dissertação (Mestrado em Direito Constitucional) - Universidade Federal Fluminense, Rio de Janeiro, 2018.

STEFFEN, Will et al. The Anthropocene: conceptual and historical perspectives. Philosophical Transactions of the Royal Society, n. 369, p. 842-867, 2011.

THOMÉ, Romeu; LAGO, Talita Martins Oliveira. Barragens de rejeitos da mineração: o princípio da prevenção e a implementação de novas alternativas. Revista de Direito Ambiental, v. 85, p. 17-39, jan./mar. 2017.

TRINDADE, Antônio Augusto Cançado. Direitos humanos e meio-ambiente: paralelo dos sistemas de proteção internacional. Porto Alegre: Sérgio Antônio Fabris, 1993.

TRINDADE, Antônio Augusto Cançado. The parallel evolutions of international human rights protection and of environmental protection and the absence of restrictions upon the exercise of recognizes human rights. In: TRINDADE, Antônio Augusto Cançado; LEAL, César Barros. Human rights and environment. Fortaleza: Expressão Gráfica e Editora, 2017, p. 49-92.

TVERSKY, Amos; KAHNEMAN, Daniel. The framing of decisions and the psychology of choice. In: ELSTER, Jon. Rational choice. Nova Iorque: New York University, 1986. p. 123-141.

VERÍSSIMO, Beto. Let's cut Amazon deforestation to zero. Here's how. Americas Quarterly, nov. 2015.

WONG, Marcela Torres. Natural resources, extraction and indigenous rights in Latin America: exploring the boundaries of environmental and State corporate crime in Bolivia, Peru and Mexico. London: Routledge, 2019.

ZANELLA, Tiago Vinicius. A aplicação da precaução no direito internacional do ambiente: uma análise à luz da proteção do meio marinho. Revista Internacional de Direito Ambiental, v. 5, n. 13, jan./abr. p. 307-332, 2016.

ZAREMBERG, Gisela; WONG, Marcela Torres. Participation on the edge: Prior consultation and extractivism in Latin America. Journal of Politics in Latin America, v. 10, n. 3, p. 29-58, 2018. 
Para publicar na revista Brasileira de Políticas Públicas, acesse o endereço eletrônico www.rbpp.uniceub.br

Observe as normas de publicação, para facilitar e agilizar o trabalho de edição. 